\title{
Homophobie und Revolutionsangst. Die politische Dramaturgie des 30. Juni 1934
}

Der Popanz revolutionärer Umbrüche, unabhängig ob diese nun real oder nur eingebildet sind, steht immer in einem engen Zusammenhang mit den ergriffenen Gegenmaßnahmen, mithilfe derer solch Schreckgespenste in allerletzter Not abgewehrt werden sollen. Sowohl der Terror und die Furcht als auch die verwendete Gewalt unterliegen dabei einem dauernden Wechselverhältnis, wobei sich die Revolutionäre und ihre Kontrahenten oftmals in einer Radikalisierungsspirale befinden - also die Gegengewalt auf die Gewalt reagiert und diese folglich in ihrer Brutalität zu übertreffen sucht. ${ }^{1}$ Zudem führen die Revolten und Revolutionen des 20. Jahrhunderts deutlich vor Augen, dass mit der Angst vor diesen ein erhebliches Mobilisierungs- und Gewaltpotenzial verbunden ist - selbst in diktatorischen Regimen wie dem NS-Staat, was insbesondere am sogenannten »RöhmPutsch" evident wird.

Um dies zu verdeutlichen, steht am Anfang der vorliegenden Untersuchung ein Zitat Werner Bests, der als Organisationschef des Sicherheitsdienstes (SD) die Aktionen der »Röhm-Morde» in Süddeutschland organisierte und als einer der wichtigsten Akteure neben Heinrich Himmler und Reinhard Heydrich bei der Entmachtung der Sturmabteilung (SA) und der Ermordung des Stabschefs Ernst Röhm gilt. ${ }^{2}$ Ohne seine zentrale Rolle bei dem Mordkomplott einzugestehen, hat

\footnotetext{
1 Zum Begriff der "Radikalisierung» vgl. neuerdings Reichardt, Sven: Radikalisierung. Zeithistorische Anmerkung zu einem aktuellen Begriff, in: Geschichte und Gesellschaft 43 (2017), S. 68-91; sowie als praktisches Beispiel für den Zeitraum von 1918 bis 1923 Göllnitz, Martin: Spirale der Gewalt. Radikalisierungsprozesse studentischer Gewalttäter in den Anfangsjahren der Weimarer Republik und der Ersten Republik Österreich, in: Jahrbuch für Universitätsgeschichte 21 (2018), S. 155 - 178.

2 Die Biographie Ernst Röhms soll hier nicht erneut rekapituliert werden, gleichwohl eine ausgewogene kritische Untersuchung seiner Person in deutscher Sprache bislang aussteht. Vgl. zu Röhms Leben die englische Studie von Hancock, Eleanor: Ernst Röhm. Hitler's SA Chief of Staff, New York 2008, insb. S. 39-60; sowie Campbell, Bruce: The SA Generals and the Rise of Nazism, Lexington (Ky) 1998, S. 8186; Fischer, Conan: Ernst Julius Röhm - Stabschef der SA und unentbehrlicher Außenseiter, in: Die braune Elite. 22 biographische Skizzen, hrsg. von Ronald Smelser/ Rainer Zitelmann, Darmstadt 1989,
} 
sich Best nach dem Zweiten Weltkrieg für seine Beteiligung zu rechtfertigen versucht. ${ }^{3}$ Gegenüber dem Generalstaatsanwalt in München erklärte er am 18. Juni 1951:

»Ich war am 30. Juni 1934 überzeugt, daß die Gefahr eines gewaltsamen Umsturzes der bestehenden Staatsordnung gegeben war. Das Verhalten zahlreicher hoher und anderer SA-Führer und die gewaltige Aufblähung der SA durch die Aufnahme von Millionen bisheriger `Marxisten`, die unklare Proklamation ssozialistischer Ziele, die Phrase von der zzweiten Revolution und die Ungeduld der unbeschäftigten, meist erwerbslosen SA-Männer ließ es als möglich erscheinen, daß diese Meldungen - von catilinarischen Führern ausgenutzt - in einen ১braunen Bolschewismusı ausarten würden. [...] Wenn z.B. die sofortige, verfahrenslose Exekution von Aufrührern und Verschwörern [...] die Gefahr für Volk und Staat bannen konnte und wenn sie hierfür wirklich notwendig war, so war sie nach meiner Meinung durch den Staatsnotstand gerechtfertigt, der - wie die erfolgreiche Revolution - bestehendes Recht bricht und dadurch neues Recht schafft. « ${ }^{4}$

Best, dem hier an einer juristischen Legitimation der Morde gelegen scheint, spricht gleich mehrere interessante Punkte an, die für die folgenden Überlegungen von Bedeutung sind. Zum einen bedient er das Stereotyp des übergelaufenen Marxisten, der sich in sogenannten »Beefsteak-Stürmen" (außen braun, innen rot) organisierte; obwohl nicht den Tatsachen entsprechend, prägte dieses Stereotyp über Jahrzehnte das öffentliche Bild von der SA. ${ }^{5}$ Zum anderen greift er auf das Motiv der Bolschewismusfurcht zurück, das die Zwischenkriegszeit ab 1918 dominierte und vor allem in Mittel- und Ostmitteleuropa zu zahlreichen Gewaltakten und Gräueltaten führte. ${ }^{6}$ Schließlich existierte mit Russland ein ganzer Staat, der scheinbar nur darauf wartete, die Gewalt der Revolution auf die übrige Welt auszudehnen - eine Gefahr, die Best im Jahr 1951, vor dem Hintergrund des aufziehenden Kalten Krieges, geflissentlich für sich zu nutzen wusste. Interessan-

\footnotetext{
S. 212-221; Fest, Joachim: Ernst Röhm und die verlorene Generation, in: Das Gesicht des Dritten Reiches. Profile einer totalitären Herrschaft, hrsg. von dems., Frankfurt a. M. 1969, S. 163 - 178.

$3 \mathrm{Zu}$ Bests Biographie und seiner Rolle beim »Röhm-Putsch» vgl. immer noch grundlegend Herbert, Ulrich: Best. Biographische Studien über Radikalismus, Weltanschauung und Vernunft 1903-1989, 3. Aufl., Bonn 1996, insb. S. 138-147.

4 Institut für Zeitgeschichte (IfZ), ZS 207/1, Werner Best, Beantwortung des Fragebogens des Generalstaatsanwalts in München vom 18.6.1951 (1JsGen. $1 \mathrm{ff} / 49$ ), S. $9 \mathrm{f}$.

5 Longerich, Peter: Geschichte der SA, München 2003, S. 193. Vgl. auch Siemens, Daniel: Stormtroopers. A New History of Hitler's Brownshirts, New Haven 2017.

6 Vgl. dazu exemplarisch Gerwarth, Robert/ Horne, John: Bolschewismus als Fantasie. Revolutionsangst und konterrevolutionäre Gewalt 1917 bis 1923, in: Krieg im Frieden. Paramilitärische Gewalt in Europa nach dem Ersten Weltkrieg, hrsg. von dens., Göttingen 2013, S. 94-107; Conway, Martin/ Gerwarth, Robert: Revolution and Counter-Revolution, in: Political Violence in Twentieth-Century Europe, hrsg. von Donald Bloxham/ Robert Gerwarth, Cambridge 2011, S. 140 - 175; Jones, Mark: Founding Weimar. Violence and the German Revolution of 1918-1919, Cambridge 2016; Barth, Boris: Dolchstoßlegenden und politische Desintegration. Das Trauma der deutschen Niederlage im Ersten Weltkrieg $1914-$ 1933 (Schriften des Bundesarchivs, Bd. 61), Düsseldorf 2003, S. 396 - 398; Schumann, Dirk: Europa, der Erste Weltkrieg und die Nachkriegszeit. Eine Kontinuität der Gewalt?, in: Journal of Modern European History 1 (2003), S. $24-43$; Weisbrod, Bernd: Gewalt in der Politik. Zur politischen Kultur in Deutschland zwischen den Weltkriegen, in: Geschichte in Wissenschaft und Unterricht 43 (1992), S. 391-404.
} 
ter noch dürfte jedoch Bests Wortwahl sein. So sei er damals davon überzeugt gewesen, es stehe eine zweite Revolution durch die SA bevor. Die Verwendung des Präteritums deutet darauf hin, dass er mittlerweile, also sechs Jahre nach dem Ende des NS-Regimes, nicht mehr an einen Putschversuch Röhms glaubte. Diese Vermutung wird durch eine weitere Formulierung erhärtet: So erklärt Best, ihm sei es lediglich als möglich erschienen, dass die vermeintliche SA-Revolte in einen "braunen Bolschewismus" ausarten könne. ${ }^{7}$

In Anbetracht der Tatsache, dass Best zu den zentralen Akteuren der »RöhmMorde» gehörte, erstaunt diese nachträglich verfasste Rechtfertigung der Aktion. Im Folgenden soll daher die politische Dramaturgie der Ereignisse, die zum 30. Juni 1934 führten, beleuchtet und hinterfragt werden. Im Mittelpunkt steht dabei die Frage, ob es sich tatsächlich um einen "Röhm-Putsch" oder vielleicht doch besser um einen "Putsch gegen Röhm « $^{8}$ - bei dem die Homophobie führender NS-Politiker, eine durch fingierte Beweise bewusst geschürte Angst vor einer SA-Revolution, die polternden Drohgebärden Röhms in Richtung Reichswehr und Parteispitze sowie das Konkurrenzgerangel innerhalb der NS-Bewegung ein unentwirrbares Motivknäuel bildeten - gehandelt hat und ob in diesem Zusammenhang die Revolutionsangst des sich in der Konsolidierungsphase befindlichen NSHerrschaftssystems eine wichtige Rolle spielte. Zur Annäherung an die Beantwortung dieser Frage gliedert sich der Beitrag in insgesamt vier Kapitel, wobei der eigentliche Mordkomplott den Ausgangspunkt darstellt.

Nach der Rekonstruktion des Tathergangs wird den einzelnen Konfliktfeldern rund um Röhm auf den Grund gegangen. Dazu zählen 1) der sattsam bekannte Konflikt mit der Reichswehr, 2) die Androhung einer zweiten nationalsozialistischen Revolution durch die SA und 3) die enge Verbindung von Homophobie und Staatsräson, die als ein Wesensmerkmal des NS-Staates nach 1934 gilt. ${ }^{9}$ Hierbei

\footnotetext{
7 IfZ, ZS 207/1, Werner Best, Beantwortung des Fragebogens des Generalstaatsanwalts in München vom 18.6.1951 (1JsGen. $1 \mathrm{ff} / 49$ ), S. 9.

8 Diese Begriffsverwendung schlägt Pretzel, Andreas: Vom Staatsfeind zum Volksfeind: Zur Radikalisierung der Homosexuellenverfolgung im Zusammenwirken von Polizei und Justiz, in: Homosexualität und Staatsräson. Männlichkeit, Homophobie und Politik in Deutschland 1900 - 1945 (Geschichte und Geschlechter, Bd. 46), hrsg. von Susanne zur Nieden, Frankfurt a. M. 2005, S. 217-252, hier S. 223, vor.

9 Eleanor Hancock nennt als weitere Gründe bzw. Akteure den Reichspräsidenten Paul von Hindenburg, "who brought pressure on Hitler to curb or destroy the SA«, sowie den Einfluss der konservativen Verbündeten des NS-Regimes und deren Intrigen. Ohne diese Faktoren im Folgenden explizit hervorzuheben, so ist es doch evident, dass sowohl Hindenburg als auch die konservativen Eliten einen Konflikt zwischen SA und Reichswehr, vor allem aber eine Fortsetzung der SA-Gewalt zu verhindern suchten. Auch homophobe Vorbehalte gegenüber der SA-Führung dürften dabei eine Rolle gespielt haben. Eine gesonderte Erörterung dieser Faktoren erscheint daher an dieser Stelle nicht zielführend, gleichwohl diese natürlich im Hintergrund der Überlegungen stets mitschwingen. Vgl. Hancock, Eleanor: The Purge of the SA Reconsidered: "An Old Putschist Trick«? In: Central European History 44 (2011), 4, S. 669-683, hier S. 670. Zu den Verschwörern innerhalb der Vizekanzlei Franz von Papens und deren Marburger Rede vom 17. Juni 1934, die ebenfalls Einfluss auf die Mordaktionen des 30. Juni 1934 nahm, siehe grundlegend Orth, Rainer: „Der Amtssitz der Opposition«? Politik und Staatsumbaupläne im Büro des
} 
wird auch den Motiven jener Einzelpersonen und Gruppen nachgespürt, die an der Ermordung des SA-Stabschefs, seiner engeren Entourage und zahlreicher politischer Gegner beteiligt waren. Dass die Vorgeschichte des 30. Juni 1934 und der Mordkomplott selbst zumindest streckenweise den Eindruck eines Sex-\&-CrimeThrillers erwecken, dürfte durchaus im Sinne der verantwortlichen Verschwörer gewesen sein.

\section{Das Mordkomplott vom 30. Juni 1934}

Die Ereignisse des 30. Juni sind im Grunde schnell umrissen und sollen an dieser Stelle nur den erzählerischen Rahmen stecken. ${ }^{10}$ Etwa eine Woche zuvor hatten Röhms innerparteiliche Gegner damit begonnen, die Schutzstaffel (SS) und die Reichswehr auf einen bevorstehenden SA-Putsch einzustimmen und entsprechende Gegenmaßnahmen vorzubereiten. Ein Termin für die Aktion stand zu diesem Zeitpunkt noch nicht fest, doch musste schnell gehandelt werden. Denn Anfang Juni hatte Röhm nach dem letzten persönlichen und zugleich versöhnlichen Gespräch mit Adolf Hitler eine Kur angetreten und einen generellen »Urlaub» der Parteiarmee für den Monat Juli angeordnet. Die Aussicht, am 1. August wieder einer »voll ausgeruht[en] und gekräftigt[en] «11 SA gegenüberzustehen, setzte das Zeitlimit für die Aktion. Um den 25. Juni beorderten Heinrich Himmler und Reinhard Heydrich sämtliche höheren SS- und SD-Führer aus dem Reich nach Berlin, wo diesen eine unmittelbar bevorstehende SA-Revolte verkündet und zugleich erste Abwehrmaßnahmen erläutert wurden. ${ }^{12}$ Doch allein die Tatsache, dass die geplante Aktion gegen Röhm und dessen Entourage auf ein Stichwort (»Kolibri«) erfolgen sollte und nicht als Reaktion auf den vermeintlichen Putsch selbst, verdeutlicht die hier praktizierte Art von Staatsschutz. Für den Fall, dass die SA

\footnotetext{
Stellvertreters des Reichskanzlers in den Jahren 1933 -1934, Köln 2016, insb. S. 451-514; Postert, André: Das Ende der konservativen Ambitionen. Franz von Papen und die Vizekanzlei im Sommer 1934, in: Historisches Jahrbuch 134 (2014), S. 340 - 371; Göllnitz, Martin: Die Marburger Rede vom 17. Juni 1934 - eine Festtagsrede mit politischer Sprengkraft?, in: Skandal!? Stadtgeschichten aus Marburg im 20. Jahrhundert, hrsg. von dems./ Sabine Mecking, Bielefeld 2021 [im Druck].

10 Neben den im Folgenden zitierten Studien vgl. ferner die älteren Arbeiten von Werner, Andreas: SA und NSDAP. "Wehrverband», "Parteigruppe» oder "Revolutionsarmee«? Studien zur Geschichte der SA und NSDAP 1920-1933, Erlangen 1965; Bennecke, Heinrich: Die Reichswehr und der "Röhm-Putsch" (Politische Studien, Beiheft, Bd. 2), München 1964; Ders.: Hitler und die SA, München 1962.

11 Das Zitat entstammt dem Urlaubsbefehl Röhms vom 8.6.1934, zit. n. Longerich, Geschichte, S. 210. 12 Dazu und zum Folgenden vgl. Sauer, Wolfgang: Die Mobilmachung der Gewalt, in: Die nationalsozialistische Machtergreifung. Studien zur Errichtung des totalitären Herrschaftssystems in Deutschland 1933/34 (Schriften des Instituts für Politische Wissenschaft, Bd. 14), hrsg. von Karl Dietrich Bracher/ Wolfgang Sauer/ Gerhard Schulz, Opladen 1960, S. 685-966, hier S. 955-958; Longerich, Geschichte, S. 215.
} 
unerwartet starken Widerstand leisten sollte, waren von der Reichswehr außerdem umfangreiche Eingreifreserven erbeten worden. ${ }^{13}$

Zu diesem Zeitpunkt waren Röhms Kontrahenten offenbar längst nicht mehr imstande, die konstruierte Aufstandsgefahr von einer realen Revolte zu unterscheiden. Die Fama von den Putschvorbereitungen, die in erster Linie auf gezielt gestreuten Falschmeldungen, Gerüchten über das Verhalten der SA und fingierten SA-Geheimbefehlen basierte, verselbstständigte sich innerhalb von Parteispitze und Reichswehr und kehrte bald schon als vermeintlich echte Bedrohung an die verschiedenen Nachrichtendienste zurück. ${ }^{14}$ Während Himmlers SS in diesem Klima der Revolutionsangst, das durch eine reichsweite Alarmstimmung zusätzlich angeheizt wurde, die technischen Details der geplanten Aktion organisierte, begab sich Hitler am 28. Juni 1934 in Begleitung von Hermann Göring und Victor Lutze nach Essen, wo sie an der Hochzeit des dortigen Gauleiters Josef Terboven teilnahmen. Einer offiziellen Darstellung der Ereignisse ist zu entnehmen, dass auf diese Weise "nach außen de[r] Eindruck absoluter Ruhe» erweckt werden sollte. ${ }^{15}$ In Essen scheint auch der Zeitpunkt für den Mordkomplott festgelegt worden zu sein, denn aus Berlin trafen beunruhigende Neuigkeiten ein: Zum einen wurde ein unmittelbar bevorstehendes Zusammentreffen Paul von Hindenburgs mit Franz von Papen, zum anderen eine zunehmende Unruhe innerhalb der SA-Stürme gemeldet. ${ }^{16}$ Noch am selben Abend befahl Hitler seinem SA-Stabschef telefonisch, für den Vormittag des 30. Juni ein SA-Führertreffen einzuberufen, das an seinem Urlaubsort Bad Wiessee stattfinden sollte. Derweil begab sich Göring nach Berlin, um die letzten Vorbereitungen für das mörderische Vorhaben zu treffen und sämtliche beteiligten Akteure in Alarmbereitschaft zu versetzen.

Am 29. Juni 1934 kam es dann fast zu einer vorzeitigen Eskalation, als eine 3.000 Mann starke SA-Standarte lautstark randalierend durch München zog. ${ }^{17} \mathrm{Al}$ lem Anschein nach erhöhte sich infolge des Vorfalls das Tempo der gesamten Aktion, wodurch auch eine blutige Abrechnung immer wahrscheinlicher wurde: Noch in der Nacht auf den 30. Juni kehrte Hitler gemeinsam mit Joseph Goebbels und Lutze nach München zurück, wo ihm der bayerische Innenminister und Gauleiter Adolf Wagner nachdrücklich versicherte, dass die Stadt unter seiner Kon-

13 Müller, Klaus-Jürgen: Reichswehr und »Röhm-Affäre». Aus den Akten des Wehrkreiskommandos (Bayer.) VII, in: Militärgeschichtliche Mitteilungen 3 (1968) 1, S. 107-144, hier S. 113 - 117.

14 Dazu und zum Folgenden vgl. Longerich, Geschichte, S. 215; Mau, Hermann: Die »Zweite Revolution« - Der 30. Juni 1934, in: Vierteljahrshefte für Zeitgeschichte 1 (1953) 2, S. 119-137, hier S. $131 \mathrm{f}$.

15 Mitteilung der NS-Korrespondenz vom 30.6.1934, zit. n. Domarus, Max: Hitler. Reden und Proklamationen 1932-1945. Kommentiert von einem deutschen Zeitgenossen, Bd. 1: Triumph, Würzburg 1962, S. 399f.

16 Longerich, Geschichte, S. 216.

17 Vgl. dazu Höhne, Heinz: Mordsache Röhm. Hitlers Durchbruch zur Alleinherrschaft 1933 - 1934, Reinbek 1984, S. $261-263$. 
trolle sei. Ohne das Eintreffen der angeforderten Verstärkung aus Berlin und Dachau abzuwarten - und lediglich in Begleitung von Göring, Lutze und Rudolf Heß sowie einem Kommando ausgesuchter SS-Männer und einiger Polizeibeamter - begab sich der "Führer" daraufhin auf direktem Weg nach Bad Wiessee. ${ }^{18}$ In der Pension Hanselbauer, wo die zur Besprechung einbestellten SA-Führer am Vorabend ausgiebig gezecht hatten und ihren Rausch ausschliefen, herrschte zu dieser Zeit noch absolute Ruhe. ${ }^{19}$ Der Münchener Gruppe gelang es daher, sämtliche Anwesenden ohne Gegenwehr zu überrumpeln und aus dem Bett heraus zu verhaften. Um Röhm kümmerte sich Hitler höchstpersönlich, der diesen geradezu hysterisch mit Vorwürfen überhäufte. ${ }^{20}$ Für die nachträgliche Legitimation der Verhaftungsaktion und die nun einsetzenden Morde war ferner der Umstand von Bedeutung, dass der Breslauer SA-Obergruppenführer Edmund Heines sein Bett mit einem jungen SA-Mann geteilt haben soll. Offenbar beflügelte der Vorfall die sexuellen Fantasien und antihomosexuellen Vorbehalte der Beteiligten, denn in den nächsten Monaten war dem NS-Regime, aber auch der Exilpresse in hohem Maße daran gelegen, die Pension als Sündenpfuhl und wahres Eldorado der Homosexualität darzustellen. ${ }^{21}$

Während die festgenommenen SA-Führer in das Gefängnis München-Stadelheim gebracht wurden, wo man sechs von ihnen noch am gleichen Tag erschoss, machten sich die Mordkommandos von SS, SD und Geheimer Staatspolizei (Gestapo) nach Erhalt des verabredeten Stichwortes auf, um die angeblichen Putschisten wie auch vermeintliche Staatskritiker im ganzen Reich zu erledigen. ${ }^{22}$ In den folgenden Tagen ermordeten sie wahrscheinlich zwischen 150 und 200 Menschen, darunter führende SA-Funktionäre, parteiinterne Gegner Hitlers wie etwa Gregor Strasser, konservative Politiker wie Edgar Jung und auch Reichswehrangehörige wie die Generäle Kurt von Schleicher und Ferdinand von Bredow. ${ }^{23}$ Röhm

18 Longerich, Geschichte, S. 216 f.; Höhne, Mordsache, S. 265-268.

19 Longerich, Geschichte, S. 217.

20 Lutze, Viktor: Reichswehr zieht auf. Tagebuch des zweiten SA-Stabschefs, in: Hannoversche Presse, vom 18.5.1957.

21 Vgl. dazu Zinn, Alexander: Die soziale Konstruktion des homosexuellen Nationalsozialisten. Zu Genese und Etablierung eines Stereotyps, Frankfurt a. M. 1997, S. 108-113, $118-122$; Ders.: Zur sozialen Konstruktion des homosexuellen Nationalsozialisten. Der "Röhm-Putsch" und Homosexuellenverfolgungen 1934/35 im Spiegel der Exilpresse, in: Capri - Zeitschrift für schwule Geschichte 18 (1995), S. 21 - 48, hier S. 23-26.

22 Vgl. dazu o.V.: Sieben SA-Führer erschossen, in: Völkischer Beobachter, Extra-Ausgabe vom 1.7. 1934. Der SA-Gruppenführer Karl Ernst wurde in Berlin erschossen. Vgl. dazu Sauer, Bernhard: Goebbels "Rabauken». Zur Geschichte der SA in Berlin-Brandenburg, in: Berlin in Geschichte und Gegenwart Jahrbuch des Landesarchivs Berlin (2006), S. 107-164. Zu den sechs in Stadelheim ermordeten SA-Führern siehe Selig, Wolfram: Ermordet im Namen des Führers. Die Opfer des Röhm-Putsches in München, in: Staat, Kultur, Politik. Beiträge zur Geschichte Bayerns und des Katholizismus, hrsg. von Winfried Becker/ Werner Chrobak, Kallmünz 1992, S. 341-356, hier S. $342-346$.

23 Bloch, Charles: Die SA und die Krise des NS-Regimes 1934, Frankfurt a. M. 1970, S. 104; Kershaw, Ian: Hitler 1889-1936, München 2002, S. 650; Longerich, Peter: Heinrich Himmler. Biographie, 3. Aufl., 
wurde dagegen am 1. Juli 1934 auf Anordnung Hitlers von Theodor Eicke, dem Kommandanten des Konzentrationslagers Dachau, und SS-Sturmbannführer Michael Lippert eine Ausgabe des »Völkischen Beobachters" sowie eine Pistole in seine Gefängniszelle in Stadelheim gebracht. Da der Stabschef der SA jedoch nicht bereit war, den ihm zugedachten Part zu übernehmen, und längere Zeit kein Schuss fiel, drangen Eicke und Lippert in dessen Zelle ein und ermordeten ihn kurzerhand. ${ }^{24}$ Noch am selben Tag berichtete die Presse über Röhms Exekution in Stadelheim: „Dem ehemaligen Stabschef Röhm ist Gelegenheit gegeben worden, die Konsequenzen aus seinem verräterischen Handeln zu ziehen. Er tat das nicht und wurde daraufhin erschossen. ${ }^{25}$

Am 2. Juli wurde der Mordkomplott, getarnt als Abwehraktion einer angeblich drohenden SA-Revolte, nachträglich als sogenannte "Staatsnotwehr" gesetzlich legitimiert. ${ }^{26}$ Bereits am Tag darauf erklärte Hitler dann in einer Ministerbesprechung, dass sich unter der Führung Röhms eine kleine Clique von SA-Führern versammelt habe, deren Zusammenhalt nicht aus ihrer Treue zur Bewegung resultierte, sondern einzig durch Ehrgeiz und eine »besondere Veranlagung" bestimmt gewesen sei. ${ }^{27}$ Obwohl er seinen SA-Stabschef immer wieder gedeckt habe, beging dieser "schwersten Verrat an seiner Person«: "Aus der unglücklichen Veranlagung des ehemaligen Stabschefs sei die minderwertige Besetzung der SA-Führerstellen zu erklären, ebenso aber auch sein bewusst geführter Kampf gegen die Wehrmacht. « Anschließend schlug der „Führer» dann den Bogen vom Kern der Verschwörer hin zu den vermeintlichen Bündnispartnern Röhms, wobei er in seiner Formulierung äußerst vage blieb und vor allem auf Gregor Strasser und Kurt von Schleicher abzielte: "Im Laufe der Zeit hätten sich die verschiedenartigsten Elemente zusammengefunden, darunter auch Kreise, die keinen Staatsstreich geplant hätten, aber an einer Lockerung des bestehenden Zustandes interessiert gewesen seien", führte Hitler weiter aus und hob außerdem hervor, dass »Röhm und die mit ihm im Komplott befindlichen SA-Führer [...] sich mit SA-Stabswa-

München 2008, S. 183. Dagegen geht Siemens, Stormtroopers, S. 169f., davon aus, dass insgesamt kaum mehr als 100 Personen ermordet wurden. Über 90 männliche sowie zwei weibliche Opfer des Mordkomplotts sind namentlich bekannt. Vgl. dazu Gritschneder, Otto: „Der Führer hat Sie zum Tode verurteilt...». Hitlers »Röhm-Putsch«-Morde vor Gericht, München 1993.

24 Nieden, Susanne zur: Aufstieg und Fall des virilen Männerhelden. Der Skandal um Ernst Röhm und seine Ermordung, in: Homosexualität und Staatsräson. Männlichkeit, Homophobie und Politik in Deutschland 1900-1945 (Geschichte und Geschlechter, Bd. 46), hrsg. von ders., Frankfurt a. M. 2005, S. 147-192, hier S. 182.

25 Zit. n. Domarus, Hitler, S. 404.

26 Goebbels, Joseph: Das Reich steht - und über uns der Führer. Rede des Reichsministers Dr. Goebbels im Rundfunk, in: Völkischer Beobachter, Nr. 184 vom 3. 7.1934.

27 Ministerbesprechung vom 3.7.1934, in: Akten der Reichskanzlei Regierung Hitler 1933 - 1938, Teil I: Die Regierung Hitler 1933/34, Bd. 2: 12. September 1933 bis 27. August 1934. Dokumente Nr. 207 bis 384, bearb. von Karl-Heinz Minuth und hrsg. von Konrad Repgen/ Hans Booms, Boppard am Rhein 1983, S. $1354 \mathrm{f}$. Dort finden sich auch die folgenden Zitate. 
chen umgeben [hätten], in die fast ausschließlich schwer vorbestrafte Subjekte aufgenommen worden seien. «28

Die Legende vom »Röhm-Putsch» war damit in ihren Grundzügen geboren und wurde lediglich in einer Reichstagsrede Hitlers vom 13. Juli 1934 noch wortreich ausgeschmückt. ${ }^{29}$ Obgleich er für seine Verschwörungstheorie keinerlei Beweise vorlegen konnte und auch in der Folgezeit den Nachweis einer realen Putschvorbereitung schuldig blieb, stellte das Gros der deutschen Bevölkerung die Mär vom "Röhm-Putsch" nicht infrage. Wie Susanne zur Nieden und Sven Reichardt betonen, war dafür nicht etwa die Glaubwürdigkeit der vom NS-Staat kolportierten Version der Ereignisse verantwortlich. Vielmehr existierten sowohl in der Bevölkerung als auch in der Spitze des NS-Staates mehr als genug Gegner der plebejischen Parteiarmee, die deren Zerschlagung nachhaltig begrüßten. ${ }^{30}$ Allzu gern war man dazu bereit, die von Hitler und der NS-Presse vorgetragene Fama einer drohenden Revolution zu akzeptieren, weil die Morde nicht nur geduldet, sondern aufgrund des SA-Terrors der vergangenen Monate im Ergebnis sogar befürwortet wurden. ${ }^{31}$ Im Folgenden soll der Problem-Komplex SA näher erläutert werden.

\section{Auf dem Weg zum Volksheer? Der Konflikt mit der Reichswehr}

Der wohl bekannteste Konflikt der SA bestand mit der Reichswehr. Bereits im Frühjahr und Sommer 1933 war es zu einer engen Kooperation beider Organisationen gekommen, wobei die Wehrmacht die Parteitruppe als künftige Dachorganisation für sämtliche vor- und paramilitärische Aktivitäten bestätigt hatte. ${ }^{32}$ Und während Röhm noch seine Sonderverbände wie Flieger- oder Marine-SA ausbaute, wurde bereits mit dem Einzug von SA-Einheiten in den Grenzschutz begonnen. Die SA entwickelte sich somit sukzessive zu einer selbstständigen und bewaffneten Macht, die als drittes Organ neben Reichswehr und Polizei agieren sollte. ${ }^{33}$ Röhms Pläne gingen allerdings vielmehr in die Richtung eines Miliz-Heeres, des-

\footnotetext{
28 Ebd., S. 1356 f.

29 Vgl. dazu Domarus, Hitler, S. 415, 421.

30 Nieden, Susanne zur/ Reichardt, Sven: Skandale als Instrument des Machtkampfes in der NS-Führung. Zur Funktionalisierung der Homosexualität von Ernst Röhm, in: Skandal und Diktatur. Formen öffentlicher Empörung im NS-Staat und in der DDR, hrsg. von Martin Sabrow, Göttingen 2004, S. 33 - 58, hier S. 56.

31 Ebd.; Kershaw, Hitler, S. 654.

32 Sauer, Mobilmachung, S. 888; Krausnick, Helmut: Der 30. Juni 1934. Bedeutung, Hintergründe, Verlauf, in: Aus Politik und Zeitgeschichte. Beilage zur Wochenzeitung "Das Parlament" vom 30. 6. 1954, B XXV/54, S. 317-324, hier S. 318f.

33 Vgl. dazu auch Longerich, Geschichte, S. 186.
} 
sen Zuständigkeit er auch im Bereich der Inneren Sicherheit und der Herrschaftssicherung des Nationalsozialismus im Allgemeinen wissen wollte. Nach Peter Longerich war der Reichswehr in diesem Szenario ausschließlich eine Hilfsfunktion zugedacht; sie sollte im Wesentlichen die Kader für die Ausbildung von Reserveeinheiten und der notwendigen militärischen Spezialisten zur Verfügung stellen. ${ }^{34}$

Ab Dezember 1933 forderte der zum Reichsminister avancierte Röhm dann immer energischer eine führende Rolle im militärischen Sektor des Deutschen Reiches und stützte sich dabei auf das gewaltige Drohpotenzial seiner Parteiarmee. Natürlich lehnte die Reichswehrführung derlei Hegemonialansprüche vehement ab, der unabhängig davon weite Teile der SA-Führung suspekt waren und der die wachsende Missstimmung innerhalb der SA-Basis keineswegs verborgen blieb. ${ }^{35}$ Röhm hatte zum Ende des Jahres 1933 jedenfalls die Debatte nach der künftigen Wehrverfassung des NS-Herrschaftssystems eröffnet, wobei weder der Reichswehr noch dem Staats- und Parteiapparat daran gelegen war, diese brisante Frage im öffentlichen Raum statt in persönlichen Gesprächen und internen Diskussionen auszutragen.

Mit dem Rückzug aus der Genfer Abrüstungskonferenz und dem Austritt aus dem Völkerbund im Oktober 1933 befand sich die Aufrüstung des NS-Regimes in einer konkreten Vorbereitungsphase. Nach dem Versailler Vertrag konnte aber jegliche illegale Militarisierung, worunter auch die Ausbildung und Bewaffnung von SA-Einheiten fiel, Sanktionen gegen das Deutsche Reich nach sich ziehen. Schon deswegen verwies die Reichswehrführung darauf, aus Gründen der Geheimhaltung sämtliche Aufrüstungsbestrebungen bei ihr zu konzentrieren. ${ }^{36}$ Mit Hitlers Zusage einer Wehrpflichtarmee wurden Röhms militärische Bestrebungen um die Jahreswende 1933/34 ohnehin Makulatur. Der SA-Stabschef wollte seine Träume eines Volks-Heeres jedoch nicht so schnell zu Grabe tragen und übersandte dem Reichswehrminister Werner von Blomberg am 1. Februar 1934 eine geradezu explosive Denkschrift: In dieser skizzierte er seine Ansichten über die künftige Rolle der Reichswehr, der er lediglich die untergeordnete Funktion eines reinen Ausbildungsheeres zugestand. ${ }^{37}$ Der Reichswehrminister, aufs Äußerste

\footnotetext{
34 Ebd.

35 Sauer, Mobilmachung, S. 938-940; Graß, Karl Martin: Edgar Jung, Papenkreis und Röhmkrise 1933/34, Diss. phil. Heidelberg 1966, S. 184-186.

36 Zum Konflikt zwischen SA und Reichswehr im Winter 1933/34 vgl. ausführlich Müller, Klaus-Jürgen: Das Heer und Hitler. Armee und nationalsozialistisches Regime 1933-1940 (Beiträge zur Militärund Kriegsgeschichte, Bd. 2), Stuttgart 1969, S. 95 -100; Höhne, Mordsache, S. 197-205. Siehe dort auch zum Folgenden.

37 Vgl. dazu und zum Folgenden Fallois, Immo von: Kalkül und Illusion. Der Machtkampf zwischen Reichswehr und SA während der Röhm-Krise 1934 (Beiträge zur politischen Wissenschaft, Bd. 75), Berlin 1994, S. 117 f.; Höhne, Mordsache, S. 200 f.; Sauer, Mobilmachung, S. 943 - 945; Müller, Heer, S. 98 f.
} 
alarmiert, erläuterte das weitere Vorgehen zunächst im Rahmen einer Befehlshaberbesprechung und wandte sich im Anschluss unmittelbar an Hitler, da er eine direkte Einigung mit der SA-Führung für aussichtslos hielt. Hitlers Entscheidung stand zu diesem Zeitpunkt bereits fest: Für eine rasche und professionelle Aufrüstung benötigte er in jedem Fall das in der Reichswehr versammelte Potenzial an militärischem Sachverstand. Darüber hinaus konnte es sich das Regime, das sich noch in der Konsolidierungsphase befand, nicht leisten, die Armee und damit die bürgerliche Elite, die hinter der Reichswehr stand, zu verärgern. Ende Februar 1934 berief Hitler daher die Spitzen der beiden konkurrierenden Organisationen zusammen, um ihnen seine Entscheidung in Bezug auf die künftige Wehrverfassung des Deutschen Reiches mitzuteilen. Für das weitere Vorhaben des Regimes, so verkündete er, sei eine reguläre Armee mit allgemeiner Wehrpflicht unabdingbar, wohingegen ihm ein Milizheer, wie Röhm es beabsichtigte, nicht zielführend erschien. Zum Abschluss der Unterredung richtete er an die anwesende SA-Führung im Allgemeinen und den Stabschef im Besonderen die deutliche Warnung, ihm in dieser Angelegenheit fortan keine Schwierigkeiten mehr zu bereiten.

Bei einer anschließenden Zusammenkunft der Obersten SA-Führung machte Röhm seinem Unmut über diese persönliche Zurücksetzung durch Hitler lautstark Luft. ${ }^{38}$ Seine Kritik blieb vermutlich nicht folgenlos, denn der Obergruppenführer Victor Lutze - der Röhm als Stabschef nach dem 30. Juni 1934 beerben sollte - trug diese Rudolf Heß zu. Es ist davon auszugehen, dass Lutzes Verrat eine bedeutsame Wegmarke des späteren Mordkomplotts darstellte. Und obwohl sich Röhm öffentlich geläutert gab und sich nach außen hin Hitlers Entscheidung fügte, war er keineswegs bereit, die ihm zugewiesene Rolle zu akzeptieren: Stattdessen propagierte er in prominenten NS-Blättern eine Revolution in Permanenz und träumte in aller Öffentlichkeit von einem durch und durch militarisierten SA-Staat; parallel zu diesen rhetorischen Kraftübungen forcierte er zudem die militärische Aufrüstung seiner politischen Soldaten. ${ }^{39}$ Röhms Kritiker und Kontrahenten konnten solche Aktivitäten durchaus als Indiz dafür deuten, dass die SA weitere Kollisionen mit der Parteiführung und der Reichswehr einkalkulierte.

38 Dazu und zu Lutzes Verrat vgl. Sauer, Mobilmachung, S. 944, 948f.; Höhne, Mordsache, S. 206; Kershaw, Hitler, S. 636.

39 Vgl. Longerich, Geschichte, S. $204 \mathrm{f}$. 
Eine "zweite nationalsozialistische Revolution«? Der Streit mit der Parteispitze

Eng verwoben mit der Aufrüstung und Militarisierung der SA war die Forderung Röhms nach einer Fortsetzung bzw. einer zweiten nationalsozialistischen Revolution. Indem er wiederholt eine solche einforderte - und dabei auch vor der Androhung von Gewalt nicht zurückschreckte - bestärkte er den Popanz des drohenden Umsturzversuches. Solche Absichten proklamierte der Stabschef unter anderem in den "Nationalsozialistischen Monatsheften", einem zentralen Ort der NS-Presse. Unter der Überschrift "S.A. und deutsche Revolution" stellte er etwa im Juni 1933 fest: "Ein gewaltiger Sieg ist errungen. Nicht der Sieg schlechthin. «40 Röhm eröffnete mit dem Beitrag die Diskussion über den Abschluss respektive die Fortsetzung dessen, was die NS-Bewegung als "Revolution» bezeichnete. ${ }^{41}$ SA und SS erklärte er sodann zu den eigentlichen "Grundpfeiler[n] des kommenden [!] nationalsozialistischen Staates", als »die unbestechlichen Garanten, dass die deutsche Revolution sich vollendet". Wer jedoch, so Röhm weiter, erst fragen müsse, was SA und SS nach der nationalsozialistischen Machtübernahme »eigentlich immer noch wollten«, der habe offenbar nichts verstanden:

»[Denn] die nationale Erhebung ist uns nicht Sinn und Zweck unseres Kämpfens, sondern nur eine Teilstrecke der deutschen Revolution, die wir durchschreiten müssen, um zum nationalsozialistischen Staat, unserem letzten Ziel, zu gelangen! Und solange das wirkliche nationalsozialistische Deutschland noch der Erfüllung harrt, hört der erbitterte, leidenschaftliche Kampf der SA und SS nicht auf. «22

In Röhms Perspektive verkörperte die konservative Elite, die für ihn nicht mehr als ein Haufen von "Spießern" und "Nörglern" war, den erbittertsten Gegner der Revolution. Er würde jedoch keineswegs dulden, dass die SA von ihrem Weg nur "einen Fußbreit abweiche» oder dass die deutsche Revolution auf halber Strecke von den satten bürgerlichen "Nicht-Kämpfern verraten wird «. ${ }^{43}$ Doch auch mit einer derart dröhnenden Rhetorik konnte der Stabschef der SA freilich nicht seinen an politischen Inhalten mangelnden Revolutionsbegriff kaschieren, womit er im Wesentlichen die Fortsetzung des plebejischen, antibürgerlich, antikommunistisch sowie antijüdisch geprägten und von latenter Gewaltbereitschaft gekenn-

40 Röhm, Ernst: S.A. und deutsche Revolution, in: Nationalsozialistische Monatshefte 4 (1933) 39, S. 251-254. Dort finden sich auch die folgenden Zitate (Hervorhebung im Original).

41 Zum nationalsozialistischen Revolutionsbegriff vgl. Hacke, Jens: Die Rechte und die Revolution. Erwartung und Deutung der "Zeitenwende» von 1933, in: Griff nach der Deutungsmacht. Zur Geschichte der Geschichtspolitik in Deutschland, hrsg. von Heinrich August Winkler, Göttingen 2004, S. 160-184. 42 Röhm, Revolution, S. 254.

43 Ders.: Nationalsozialistische Revolution und SA, in: Hochschule und Ausland. Monatsschrift für Kulturpolitik und zwischenstaatliche geistige Zusammenarbeit 12 (1934) 6, S. 1-22, hier S. $19 \mathrm{f}$. 
zeichneten Aktionismus seiner politischen Soldaten meinte. ${ }^{44}$ Kurz gesagt blieb die »Deutsche Revolution" in Röhms einseitig-soldatischer Denkweise auf eine umfassende Militarisierung der deutschen Gesellschaft reduziert, die im Sinne einer lautstark proklamierten Volksgemeinschaft auf den "SA-Geist" ausgerichtet werden sollte. ${ }^{45}$ Für Röhm bedeutete die Fortführung der Revolution folglich, den Einfluss der konservativen Koalitionäre in Politik, Wirtschaft und Gesellschaft zu zerschlagen, das bereits mit dem »Bazillus der Verbürgerlichung» infizierte Bonzentum innerhalb der NS-Bewegung zurückzudrängen und zu guter Letzt den kämpferischen Flügel der SA-Männer zu stärken. Mit solchen Aussprüchen meldete er zugleich den Anspruch der SA an, im noch jungen NS-Staat eine führende Rolle zu übernehmen; mit der eingeschränkten Aufgabenstellung einer lediglich untergeordneten Propaganda- oder Hilfstruppe der Nationalsozialistischen Deutschen Arbeiterpartei (NSDAP) wollte er sich hingegen nicht abfinden. Hitlers "einziger Nebenbuhler «46 unter den führenden Nationalsozialisten, der ihm tatsächlich gefährlich werden konnte, positionierte sich mit seinen polternden Äußerungen bedrohlich nah am Rande einer parteiinternen Revolte. An seine Gegner in Staat und Partei, die "Spießerseelen«, hatte Röhm schon im Juni 1933 eine überdeutliche Warnung gerichtet: "Ob es ihnen paßt oder nicht, wir werden unseren Kampf weiterführen. Wenn sie endlich begreifen, um was es geht: mit ihnen! Wenn sie nicht wollen: ohne sie! Und wenn es sein muß: gegen sie! «47

Mit derart massiven und offenen Drohgebärden, begleitet von einer deutlich vernehmbaren Kritik am politischen Kurs der Regierung, zeigte Röhm für jedermann sichtbar, dass er nicht gewillt war, die Rolle eines blinden Befehlsempfängers der Parteiführung zu spielen, dem es an eigenem politischen Willen mangelte. Der NS-Führung blieb also kaum etwas anderes übrig, als daraufhin Gegenmaßnahmen einzuleiten. Denn in den militanten Äußerungen Röhms schwang nicht zuletzt der revolutionäre Anspruch der SA-Basis mit, der die neue Regierung befürchten ließ, »weitere innenpolitische Unruhen und Mitbestimmungsforderungen könnten nur auf Kosten der gerade in der Macht etablierten

44 Vgl. dazu Siemens, Daniel: Prügelpropaganda. Die SA und der nationalsozialistische Mythos vom "Kampf um Berlin», in: Berlin 1933 - 1945, hrsg. von Michael Wildt/ Christoph Kreutzmüller, München 2013, S. 33 - 49; Müller, Yves: »...wie ist's denn mit dir, Hans...?«. Männlicher Habitus, Kameradschaft und Männerbund in der SA, in: Bürgerkriegsarmee. Forschungen zur nationalsozialistischen Sturmabteilung (SA), hrsg. von dems./ Reiner Zilkenat, Frankfurt a. M. 2013, S. 355 - 371; Kühne, Thomas: Zwischen Männerbund und Volksgemeinschaft. Hitlers Soldaten und der Mythos der Kameradschaft, in: Archiv für Sozialgeschichte 38 (2008), S. 165 - 189; Balistier, Thomas: Gewalt und Ordnung. Kalkül und Faszination der SA, Münster 1989.

45 Longerich, Geschichte, S. 180. Siehe dort auch zum Folgenden. Zum Zusammenhang von Volksgemeinschaft und Gewalt vgl. grundlegend Wildt, Michael: Volksgemeinschaft als Selbstermächtigung. Gewalt gegen Juden in der deutschen Provinz 1919 bis 1939, Hamburg 2007.

46 Mau, Zweite Revolution, S. 136.

47 Röhm, Revolution, S. 254 (Hervorhebung im Original). 
NSDAP erfolgen « ${ }^{48}$ Weiterhin bedrohte die lautstark und aggressiv hervorgebrachte Forderung einer Revolutionsfortführung die gerade erst mühsam erreichte Zusammenarbeit mit den konservativen Eliten aus Wirtschaft, Armee und Beamtentum. Diese wollte man aber unter keinen Umständen verärgern. Oder anders gesagt: Hatte die NS-Bewegung vor 1933 von dem anti-bürgerlichen Habitus der draufgängerischen und gewaltbereiten SA-Männer profitiert, so betrachtete der staatstragende Nationalsozialismus diese soziale Hexis zunehmend als unkalkulierbares Risiko.49 Etliche SA-Männer stellten nach eigenem Dafürhalten aber noch immer den elitären Kern der nationalsozialistischen Volksgemeinschaft dar und manche widersetzten sich sogar der von Partei und Staat geforderten habituellen Umstellung und gesellschaftlichen wie politischen Unterordnung. ${ }^{50}$ Ihr Verlangen nach einer Fortsetzung der "nationalen Revolution" und ihr brutales, unangepasstes, die Konsolidierung des NS-Regimes gefährdendes Verhalten wurden allerdings zunehmend als lästig empfunden.

Folgerichtig erklärte Hitler dann auch am 6. Juli 1933 auf einer Konferenz der Reichsstatthalter die nationalsozialistische Revolution offiziell für beendet. Diese sei freilich »kein permanenter Zustand«; vielmehr müsse der »freigewordene Strom der Revolution« nun »in das sichere Bett der Evolution« hinübergeleitet

\footnotetext{
48 Longerich, Geschichte, S. 182.

49 Vgl. Jasmin, Mathilde: Zur Rolle der SA im nationalsozialistischen Herrschaftssystem, in: Der »Führerstaat«. Mythos und Realität. Studien zur Struktur und Politik des Dritten Reiches (Veröffentlichungen des Deutschen Historischen Instituts London, Bd. 8), hrsg. von Gerhard Hirschfeld/ Lothar Kettenacker, Stuttgart 1981, S. 329-360, hier S. 349; Müller, Yves: Männlichkeit und Gewalt in der SA am Beispiel der "Köpenicker Blutwoche», in: SA-Terror als Herrschaftssicherung. »Köpenicker Blutwoche» und öffentliche Gewalt im Nationalsozialismus, hrsg. von Stefan Hördler, Berlin 2013, S. 130 - 146, hier S. 145; Göllnitz, Martin: Entgrenzte Männerkameraderie, gewalttätige Volksgemeinschaft. Perspektiven auf die Neustadter SA, in: Volksgemeinschaft in der Gauhauptstadt. Neustadt an der Weinstraße und der Nationalsozialismus, hrsg. von Markus Raasch, Münster 2020, S. 111-124.

50 Hier kann freilich nicht en détail die enorme Bedeutung thematisiert werden, die der SA, Propagandatruppe und paramilitärischer Verband zugleich, im Rahmen der NS-Machtübernahme zufiel, zumal etwa die Hälfte aller Nationalsozialisten vor 1933 in diesem Männerbund organisiert war. Es ist in der neueren Forschung jedoch Konsens, dass die Parteitruppe als gelebte Gemeinschaft im Kleinen erprobte, was nach 1933 zum politischen Großprojekt des NS-Regimes avancierte: Die Zerstörung der bürgerlichen Gesellschaft und die Etablierung einer neuen, rassistischen Ordnung. In der SA trat somit die für den Nationalsozialismus typische Ambivalenz von Ordnung auf der einen und Destruktion auf der anderen Seite besonders hervor. Vgl. exemplarisch Reichardt, Sven: Faschistische Kampfbünde. Gewalt und Gemeinschaft im italienischen Squadrismus und in der deutschen SA (Industrielle Welt, Bd. 63), 2. Aufl., Köln 2009; Ders.: Die SA im »Nachkriegs-Krieg», in: Nationalsozialismus und Erster Weltkrieg (Schriften der Bibliothek für Zeitgeschichte, Bd. 24), hrsg. von Gerd Krumeich, Essen 2010, S. 243 - 259; Ders.: Vergemeinschaftung durch Gewalt. Das Beispiel des SA-»Mördersturmes 33" in Berlin-Charlottenburg zwischen 1928 und 1932, in: Entgrenzte Gewalt: Täterinnen und Täter im Nationalsozialismus (Beiträge zur Geschichte der nationalsozialistischen Verfolgung in Norddeutschland, Bd. 7), hrsg. von Herbert Diercks, Bremen 2002, S. 20 - 36; Siemens, Daniel: Politische Gewalt als emotionale Befriedigung. Richard F. Behrendts vergessener Geniestreich aus dem Jahr 1932, in: Zeithistorische Forschungen/Studies in Contemporary History 13 (2016), S. 172 -178; Schumann, Dirk: Gewalt als Methode der nationalsozialistischen Machteroberung, in: Das Jahr 1933. Die nationalsozialistische Machteroberung und die deutsche Gesellschaft (Dachauer Symposien zur Zeitgeschichte, Bd. 9), hrsg. von Andreas Wirsching, Göttingen 2009, S. $135-155$.
} 
werden. ${ }^{51}$ Diesen Standpunkt bekräftigte nur fünf Tage später auch der Reichsinnenminister Wilhelm Frick in einem Rundschreiben, in dem er noch einmal deutlich machte, dass jeder, der jetzt noch "von einer Fortsetzung der Revolution oder von einer zweiten Revolution" spreche, sich "gegen den Führer selbst auflehn[e] und dementsprechend behandelt" werde. ${ }^{52}$ Auch Hermann Göring, Joseph Goebbels und Rudolf Heß schlossen sich dieser Sichtweise an und stellten sich damit im Revolutionsstreit auf die Seite Hitlers. ${ }^{53}$

In der Folgezeit dämpfte Röhm zwar seine Forderung nach einer Revolution in Permanenz, doch sein eigentliches Vorhaben, die SA zu einem zentralen Faktor des NS-Herrschaftssystems auszubauen, verfolgte er weiter. Es ging schließlich nicht nur um machtpolitische Ambitionen des Stabschefs. Das eigentliche Problem bestand darin, dass es seiner Organisation, die zunehmend einer parastaatlichen Miliz glich, an Zielen und Aufgabenfeldern fehlte. Mit Abschluss der „Kampfzeit» und nach Beendigung der Gleichschaltungsaktionen begünstigte diese Orientierungslosigkeit mitunter "Verselbständigungstendenzen «"54 innerhalb der SA-Basis. Die Folge war ein kaum zu kontrollierender Terror der ebenso gefürchteten wie mitgliederstarken Parteiarmee, deren zum Teil ausufernde Gewaltexzesse oft nur durch das Eingreifen staatlicher Repressionsorgane eingehegt werden konnten, wie der erste Gestapo-Chef Rudolf Diels in seiner Autobiographie "Lucifer ante portas" wiederholt unterstreicht. ${ }^{55}$

Es galt also, die Rolle der SA neu zu definieren, weshalb Röhm fortan die Strategie verfolgte, die Parteiarmee sukzessive zu vergrößern und organisatorisch zu verselbstständigen, um daran anschließend machtpolitische Funktionen im neuen Staat zu usurpieren. Bis Mitte des Jahres 1934 wuchs seine verhinderte Revolutionsarmee auf etwa viereinhalb Millionen Mitglieder an. ${ }^{56}$ Offenkundig oblag er der Fehleinschätzung, analog zur Endphase der Weimarer Republik durch eine zahlenmäßige Verstärkung und militärische Aufrüstung der SA die Parteiführung vor vollendete Tatsachen stellen zu können. Ende des Jahres 1933 nahm Röhm dann seine Forderungen nach einer Fortsetzung der »Deutschen Revoluti-

51 Adolf Hitler über Staat und Wirtschaft, in: Völkischer Beobachter, Nr. 189 vom 8. 7.1933.

52 Ursachen und Folgen. Vom deutschen Zusammenbruch 1918 und 1945 bis zur staatlichen Neuordnung Deutschlands in der Gegenwart, Bd. 9: Das Dritte Reich. Die Zertrümmerung des Parteienstaates und die Grundlegung der Diktatur, hrsg. und bearb. von Herbert Michaelis, Berlin 1964, Nr. 2102.

53 Vgl. dazu Longerich, Geschichte, S. $182 \mathrm{f}$.

54 Jasmin, Rolle, S. 334.

55 Vgl. ausführlich Diels, Rudolf: Lucifer ante portas. Es spricht der erste Chef der Gestapo, Stuttgart 1950. Diels Ausführungen müssen freilich mit der gebotenen kritischen Distanz gelesen werden, da sie zum einen von dessen eigenen brutalen Maßnahmen ablenken und zum anderen verschleiern, dass er mit der SA und SS mehrfach eng zusammengearbeitet hat.

56 Dazu und zum Folgenden vgl. Longerich, Geschichte, S. $183 \mathrm{f}$. 
on« wieder auf. In einem groß aufgemachten Artikel äußerte er sich erneut zu dem Thema »Die SA im neuen Staat«:

»Wenn der Soldat um einer guten oder schlechten Politik willen kämpfen und werben soll, will er über diese Politik auch zu bestimmen haben! [Nationalsozialismus meint] die Auflehnung des Soldatentums [...] gegen das widersinnige Prinzip einer Führung der Politik durch Menschen und Kräfte, die nicht bereit oder fähig sind, für die Folgen ihres Tuns mit Leib und Leben einzutreten.«57

Röhm bezog sich damit keineswegs auf den rein weltanschaulichen Bereich; vielmehr hatten seine Revolutionsforderungen ganz handfeste Ziele vor Augen. Fassbar wird dies zum Beispiel am kämpferischen Ton, den er in einer Rede im April des Jahres 1934 anschlug: Im Verlauf seiner Ausführungen beklagte er das Verhalten des NS-Staates während der Machtübernahme, da mit den »Trägern und Handlangern des alten und noch älteren Systems" in »einer unbegreiflichen Milde« umgegangen worden sei, woraus der Stabschef schlussfolgerte, dass man sich weiterhin "mitten in dem gewaltigen Geschehen der nationalsozialistischen Revolution", deren "kämpferische Willensträgerin" im Kern die SA darstelle, befinde. ${ }^{58}$ Einmal mehr war es also Ernst Röhm, der die Revolutionsdebatte im öffentlichen Raum lostrat. Die Parteiführung reagierte umgehend auf den erneuten Affront und richtete abermals warnende Worte an die SA. Immer stärker kristallisierte sich nun heraus, dass die SA unter Röhm einen Herd ständiger Unruhe bildete. Für die NSDAP war dieser Zustand auf Dauer unhaltbar, zumal hinter der Forderung der SA-Führung ein nur schwer zu kontrollierendes, überwiegend unzufriedenes und weitgehend verarmtes, außerdem potenziell gewaltbereites Millionenheer stand, das seinen antibürgerlichen und militanten Habitus mithilfe einer »Politik der Straße» kultiviert hatte. ${ }^{59}$ Indem die Parteispitze um Hitler diese "Mammutorganisation mit ihrem uneingelösten Machtanspruch" weiterhin duldete, gefährdete sie in hohem Maße die mühsam etablierte Verständigungsbasis mit den Eliten aus Wirtschaft, Reichswehr und Beamtentum. ${ }^{60}$ Der schwelende Konflikt mit der SA verband sich überdies mit einer Reihe zusätzlicher, zum Teil äußerst brisanter Fragen: Weithin ungeklärt waren zu diesem Zeitpunkt die Per-

57 Röhm, Ernst: Die S.A. im neuen Staat, in: Der SA-Mann, Nr. 50 vom 16.12.1933. Zur Wochenzeitung "Der SA-Mann" siehe Wahl, Hans Rudolf: Die illustrierte NS-Wochenzeitung "Der SA-Mann" 1932 1934: Ein Beitrag zur Ästhetik des SA-Faschismus, in: Jahrbuch für Kommunikationsgeschichte 15 (2013), S. $123-138$.

58 Vgl. dazu o.V.: Revolution und die S.A., in: Völkischer Beobachter, Nr. 109 vom 19.4.1934.

59 Zum antibürgerlichen Habitus und Gewaltpotenzial der SA vgl. Reichardt, Nachkriegs-Krieg; Siemens, Gewalt; Fülberth, Johannes: Bürgerkriegsarmee in permanenter »Notwehr«?, in: Bürgerkriegsarmee. Forschungen zur nationalsozialistischen Sturmabteilung (SA), hrsg. von Yves Müller/ Reiner Zilkenat, Frankfurt a. M. 2013, S. 31-44; Bessel, Richard: Political Violence and the Rise of Nazism. The Storm Troopers in Eastern Germany 1925 - 1934, New Haven 1984; Müller, Männlichkeit, S. 130 - 146.

60 Longerich, Geschichte, S. 208. 
son und die Stellung des neuen Staatsoberhauptes, der Einfluss der bürgerlichkonservativen Kräfte und die künftige Wehrverfassung. Kurz gesagt stand die "Grundordnung des NS-Staates» im Frühjahr 1934 zur Debatte. ${ }^{61}$

Vor dem Hintergrund der Revolutionsforderungen, der unruhigen SA-Basis und der massiven Drohgebärden Röhms fiel es dessen inner- wie außerparteilichen Kontrahenten sicherlich leicht, kleinste Hinweise in handfeste Indizien für einen unmittelbar bevorstehenden SA-Putsch umzudeuten. Konservative Kräfte ebenso wie die neu etablierten Eliten der NSDAP mussten sich angesichts der anhaltenden Gewaltexzesse der SA in ihrer politischen wie ökonomischen Existenz bedroht gefühlt haben - gleichwohl keine Rede davon sein kann, dass Röhm im Frühjahr 1934 tatsächlich einen Putsch vorbereitete.

\section{Angst vor einer homosexuellen Verschwörung? Der Konflikt innerhalb der NS-Bewegung}

Kommen wir zum letzten Punkt. In der von Hitler formulierten amtlichen Presseerklärung, die am 1. Juli 1934 im »Völkischen Beobachter« erschien, ist zu lesen, dass »einzelne Elemente» seit Monaten das Verhältnis zwischen der SA und der Partei sabotiert hätten, um so den Staat zu destabilisieren.62 Dieses arglistige Vorhaben schrieb Hitler einer "bestimmt eingestellten Clique» um Röhm zu, der derartige Tendenzen aufgrund seiner »bekannte[n] unglückliche[n] Veranlagung» sogar gefördert habe. In einem weiteren Artikel der gleichen Ausgabe werden diese antihomosexuellen Ressentiments aufgegriffen und näher ausgeführt. Demnach bot sich dem »Führer" und seinen Leuten in der Pension Hanselbauer »ein schamloses Bild«:

»Heines lag mit einem homosexuellen Jüngling im Bett. Die widerliche Szene, die sich dann bei der Verhaftung von seinem Genossen abspielte, ist nicht zu beschreiben. Sie wirft schlagartig ein Licht auf die Zustände der Umgebung des bisherigen Stabschefs, deren Beseitigung dem entschlossenen, tapferen und unerschrockenen Handeln des Führers zu verdanken ist. [...] Die Früchte dieser Säuberungsaktion wird das geeinte deutsche Volk ernten. « ${ }^{63}$

Die NS-Führung setzte hier zweifellos auf die Wirkung eines Sex-Skandals, den sie eigenhändig inszenierte und der auf der Zustimmung einer weitgehend homo-

61 Ebd.

62 O.V.: Eine Verlautbarung der Reichspressestelle, in: Völkischer Beobachter, Sondernummer vom 1.7.1934.

63 O.V.: Die Aktion des Führers, in: Völkischer Beobachter, Sondernummer vom 1.7.1934. 
phoben Bevölkerung beruhte. ${ }^{64}$ Mithilfe der populistischen Töne, die in der Tagespresse angeschlagen wurden, ließen sich die komplizierten Machtkämpfe überdecken, die sich zwischen Reichswehr, SA, konservativem Bürgertum und SS abgespielt hatten. Wie inszeniert dieser Skandal in Wirklichkeit war, der die Fama einer drohenden SA-Revolution mit dem Mythos einer homosexuellen Verschwörung verwob, und wie eng dieser in den Konkurrenzkampf innerhalb der NS-Bewegung eingebettet war, offenbart ein Blick in die Endphase der Weimarer Republik: In den Jahren 1931 und 1932 hatte Röhm aufgrund seiner Homosexualität schon einmal im Zentrum eines Eklats gestanden und war nur knapp einer Anklage nach Paragraph 175 des Strafgesetzbuches entgangen. ${ }^{65}$

Den Auslöser der Affäre markieren drei Briefe, die Röhm Ende 1928 und zu Beginn des Jahres 1929 verfasst hatte und in denen er unverhohlen seine Vorliebe für homoerotische Abenteuer beschrieb. Nachdem die Presse, allen voran sozialdemokratische Zeitungen, von diesen Briefen erfahren hatte, startete sie im Jahr 1931 eine groß angelegte Kampagne, bei der alle Register der Sexualdenunziation gezogen und Röhms erotische Neigung öffentlich gegeißelt wurde. ${ }^{66}$ Einschlägige Informationen über dessen Sexualleben erhielt die Presse sowohl von politischen Gegnern der NSDAP als auch von innerparteilichen Konkurrenten des Stabschefs. Während erstere hofften, den Nationalsozialisten auf diese Weise politisch zu schaden, verfolgten Röhms Kontrahenten offenbar den Plan, diesen gesellschaftlich zu kompromittieren und somit machtpolitisch kaltzustellen. Noch im Februar desselben Jahres sprach sich dann Hitler mit einem äußerst ungewöhnlichen Erlass für seinen Parteifreund aus und kritisierte in diesem, dass gegen Röhm und andere höhere SA-Führer mehrere Meldungen und Anzeigen vorlägen, die vor allem "Angriffe gegen das Privatleben dieser Persönlichkeiten " enthielten. ${ }^{67}$ Er weise es aber "grundsätzlich und in aller Schärfe zurück», über Dinge, die »rein auf privatem Gebiet« lägen, zu entscheiden, zumal die SA »eine Zusammen-

\footnotetext{
64 Nieden/ Reichardt, Skandale, S. 35f. Siehe dort auch zum Folgenden.

65 Die reichsweite Kriminalisierung männlicher Homosexualität muss als ein Ergebnis der Reichsgründung von 1871 betrachtet werden. Denn obgleich "Sodomiterei« bereits seit 1794 in Preußen bestraft wurde, galt sie in vielen süddeutschen Ländern vor 1871 aufgrund des Einflusses des französischen "Code pénal« als straffreie Handlung. Erstmals war der § 175 am 31 . Mai 1870 mit dem neuen Strafgesetzbuch des Norddeutschen Bundes in Kraft getreten und wurde im Folgejahr reichsweit übernommen. Vgl. Herzer, Manfred: Deutsches Schwulenstrafrecht vor der Gründung des zweiten Kaiserreiches (1795 1870), in: Die Geschichte des § 175: Strafrecht gegen Homosexuelle. Katalog zur Ausstellung in Berlin und in Frankfurt am Main 1990, hrsg. von den Freunden eines Schwulen Museums in Berlin e.V., Berlin 1990, S. $30-41$. Zur Verfolgung von Homosexuellen im NS-Regime vgl. u. a. Zinn, Alexander: "Aus dem Volkskörper entfernt«? Homosexuelle Männer im Nationalsozialismus, Frankfurt a. M. 2018; Jellonnek, Burkhard: Homosexuelle unter dem Hakenkreuz. Die Verfolgung von Homosexuellen im Dritten Reich, Paderborn 1990; sowie die Beiträge in Ders./ Lautmann, Rüdiger (Hrsg.): Nationalsozialistischer Terror gegen Homosexuelle. Verdrängt und ungesühnt, Paderborn 2002.

66 Zinn, Konstruktion, S. 44-47; Jellonnek, Homosexuelle, S. 61-64.

67 Zit. n. Bennecke, Hitler, S. 253.
} 
fassung von Männern zu einem bestimmten politischen Zweck« sei. Weiter heißt es in dem Erlass:

"Sie ist keine moralische Anstalt zur Erziehung von höheren Töchtern, sondern ein Verband rauer Kämpfer. [...] Das Privatleben kann nur dann Gegenstand der Betrachtung sein, wenn es wesentlichen Grundsätzen der nationalsozialistischen Anschauung zuwiderläuft.«68

Zusätzlich wurde das Gerede um Röhms Homosexualität durch Untersuchungen der Münchener Polizei befeuert, die seit Anfang April 1931 gegen einen arbeitslosen Kellner ermittelte, der den prominenten Stabschef zu erpressen versuchte. ${ }^{69}$ Dessen Kontaktsuche im großstädtischen Strichermilieu, besonders im Berliner und Münchener Raum, gestaltete sich aufgrund seiner Popularität naturgemäß zunehmend riskanter. Es waren in erster Linie die sozialdemokratischen Zeitungen, die solche Gerüchte aufgriffen, um den "Sittenverfall" sowie die Doppelmoral der Nationalsozialisten zu brandmarken und um den Eindruck einer homosexuellen Cliquen- und Günstlingswirtschaft $\mathrm{zu}$ evozieren. ${ }^{70}$ An der denunziatorischen Pressekampagne beteiligten sich gleichfalls kommunistische und bürgerliche Organe, die ebenso homophobe Vorurteile bedienten, mithilfe derer die Führungsspitze der NSDAP politisch-moralisch diskreditiert werden sollte. ${ }^{71}$ De facto besaß die Angelegenheit allerdings kaum politische Sprengkraft, da die polizeiliche Ermittlung Röhm nach Paragraph 175 keine Straftat nachweisen konnte und die erste Enthüllungswelle der "Münchener Post» sogar nachweislich auf fingierten Berichten fußte. Dass die sogenannte »Röhm-Affäre» trotzdem immer wieder für Schlagzeilen sorgte und kurz vor den Reichspräsidentenwahlen des Jahres 1932 erneut aufflammte, lag wohl vor allem an den erstaunlichen Ereignissen, die sich hinter den Kulissen abspielten.

Augenscheinlich waren die Vertreter unterschiedlichster staatlicher Instanzen nachhaltig daran interessiert, der sozialdemokratischen Presse seriöses Beweismaterial zuzuspielen und so die Berichterstattung über Röhms Homosexualität und die nationalsozialistische Doppelmoral am Laufen zu halten. Hinter diesem staatspolitischen Ränkespiel, an dem Vertreter der preußischen wie auch der Reichsregierung beteiligt waren, stand die Hoffnung, die Machtübertragung an Hitler zu verhindern, zumindest aber hinauszuzögern. Die sexuellen Vorlieben

\footnotetext{
68 Ebd.

69 Landesarchiv Berlin, A/Rep. 358, Nr. 517, Ermittlungsabschriften der Staatsanwaltschaft München. 70 Nieden/ Reichardt, Skandale, S. 37. Siehe dort auch zum Folgenden. Vgl. ferner Zinn, Konstruktion, S. 45 .

71 Zur überwiegend homophoben Berichterstattung vgl. Jellonnek, Homosexuelle, S. 62 - 65; Zinn, Konstruktion, S. 45-49; Eissler, Wilfried U.: Arbeiterparteien und Homosexuellenfrage. Zur Sexualpolitik von SPD und KPD in der Weimarer Republik (Sozialwissenschaftliche Studien zur Homosexualität, Bd. 1), Berlin (W) 1980, S. 109 f.
} 
und Neigungen seines politischen Mitkämpfers stellten aus ihrer Perspektive ein probates Mittel dar, um das Image der NSDAP zu schädigen.72 Sie spielten dem sozialdemokratischen Pressedienst daher drei authentische Privatbriefe, die im vorangegangenen Ermittlungsverfahren beschlagnahmt worden waren, und ein polizeiliches Vernehmungsprotokoll Röhms zu, aus denen sich zwar weder der Vorwurf der Päderastie noch ein Strafbestand im Sinne des Paragraphen 175 ableiten ließ, die aber klassische homophobe wie rassistische Ressentiments der Rezipienten bedienten.

In den abgedruckten Briefen hatte Röhm dem jungen Arzt Karl Günter Heimsoth seinen Weg in die Homosexualität geschildert. ${ }^{73}$ Zwei kurze Auszüge mögen dies verdeutlichen:

"Ich bilde mir ein gleichgeschlechtlich zu sein, habe dies aber richtig erst 1924 entdeckt. Ich kann mich vorher an eine Reihe auch gleichgeschlechtlicher Gefühle und Akte bis in meine Kindheit erinnern, habe aber auch mit vielen Frauen verkehrt. Allerdings nie mit besonderem Genuß. Auch drei Tripper habe ich mir erworben, was ich später als Strafe der Natur für widernatürlichen Verkehr ansah. Heute sind mir alle Frauen ein Greuel $[\ldots] . \aleph^{74}$

An anderer Stelle ist zu lesen:

»Mit dem Herrn Alfred Rosenberg, dem tölpelhaften Moralathleten, stehe ich im schärfsten Kampf. Seine Artikel sind auch vor allem an meine Adresse gerichtet; da ich aus meiner Einstellung keinen Hehl mache. Das mögen Sie daraus ersehen, daß man sich bei mir eben an diese verbrecherische Eigenart in den nat.soz. Kreisen gewöhnen hat müssen. [...] Die blutjungen frischen Leutnants würden Ihnen sicher auch gefallen [...] aber, leider... Natürlich unmöglich. Oder hätten Sie für junge Neger in Uniform etwas übrig? «75

Anfang März 1932, kurz nachdem Joseph Goebbels Hitlers Kandidatur für das Amt des Reichspräsidenten offiziell bekannt gegeben hatte, wurden Abschriften dieser Briefe in einer höchst professionell organisierten Kampagne unter sozialdemokratischer Federführung der Öffentlichkeit übergeben. ${ }^{76}$ Nach zeitgenössischen Einschätzungen war Röhms politisches Image infolge der Presseberichterstattung schwer angeschlagen. Falls sich dessen innerparteiliche Konkurrenten davon einen Vorteil erhofft hatten, so wurden sie allerdings jäh enttäuscht. Denn

72 Eine ausführliche Darstellung dieser Ereignisse findet sich bei Nieden, Aufstieg, S. 167-173; sowie bei Machtan, Lothar: Hitlers Geheimnis. Das Doppelleben eines Diktators, Berlin 2001, S. 211-225.

73 Zu den Briefen und zur Person Karl Günter Heimsoths vgl. Nieden, Aufstieg, S. 152 - 163.

74 Röhm an Dr. Karl Heimsoth, 25.2.1929, zit. n. Heinersdorf, Herbert: Akten zum Fall Röhm (II. Teil), in: Mitteilungen des Wissenschaftlich-humanitären Komitees 33 (1932), S. 383 - 396, hier S. 394 (Hervorhebung im Original). Hinter dem Pseudonym »Heinersdorf» verbirgt sich der Sexualwissenschaftler und Angehörige der Kommunistischen Partei Deutschlands (KPD) Richard Linsert.

75 Röhm an Dr. Karl Heimsoth, 3.12.1928, zit. n. ebd., S. 391 f. (Hervorhebung im Original).

76 Nieden, Aufstieg, S. 170. 
Hitler stellte sich erneut vor seinen SA-Stabschef und sprach diesem am 6. April 1932 in einer Pressemitteilung unmissverständlich sein Vertrauen aus:

"Oberstleutnant Röhm bleibt mein Stabschef, jetzt und nach den Wahlen. An dieser Tatsache wird auch die schmutzigste und widerlichste Hetze, die vor Verfälschungen, Gesetzesverletzungen und Amtsmissbrauch nicht zurückschreckt und ihre gesetzesmäßige Sühne finden wird, nichts ändern.«77

Obgleich Hitlers Machtwort der »Röhm-Affäre» ein vorläufiges Ende bereitete, stieß dessen uneingeschränkter Rückhalt für den homosexuellen SA-Stabschef bei vielen Mitgliedern der NSDAP auf Befremden, da sie einerseits selbst homophobe Vorurteile hegten und weil sie zum anderen befürchteten, der öffentliche Skandal gefährde eine erfolgreiche Etablierung der Partei auf staatspolitischer Ebene. Für die nach Ansehen, Staatsfähigkeit und Macht strebenden Nationalsozialisten entwickelte sich die Pressekampagne, die sich nicht gegen Röhm allein, sondern gegen die Bewegung als Ganzes richtete, faktisch zu einer beunruhigenden politischen Bedrohung, besonders weil die Partei in der Öffentlichkeit zunehmend als »offen oder latent homosexuelle ıKamarilla` perverser oder verbrecherischer Elemente" charakterisiert wurde. ${ }^{78}$ Tief beunruhigt über den politischen Schaden, der aus dem Skandal erwachsen könne, planten im März 1932 schließlich einige Nationalsozialisten um den Parteirichter Walter Buch, den SA-Stabschef sowie einige seiner engsten Vertrauten zu ermorden. Das Attentatsvorhaben flog jedoch im Vorfeld auf, da einer der gedungenen Mörder das Gefühl hatte, einer "Schnapsidee» aufgesessen zu sein und sich seinen potenziellen Opfern anvertraute. ${ }^{79}$

Infolge der Pressekampagnen 1931/32 nahm die Legende, der Nationalsozialismus sei eine von Homosexuellen dominierte Bewegung, allmählich Gestalt an und verdichtete sich letztlich zum Stereotyp vom "homosexuellen Nazi«. ${ }^{80}$ Innerhalb der Exilpresse überschlug man sich sogar in Verdächtigungen darüber, welche prominenten NS-Führer ähnliche Neigungen besäßen, wobei Rudolf Heß (»Frau Hitler») und Reichsjugendführer Baldur von Schirach sich besonderer Beliebtheit erfreuten. ${ }^{81}$ Auch Hitlers angebliche Homosexualität wurde wiederholt

\footnotetext{
77 O.V.: Hitler hält zu Röhm, in: Bayerischer Kurier, Nr. 98 vom 7.4.1932.

78 Nieden, Aufstieg, S. 173.

79 Dornheim, Andreas: Röhms Mann fürs Ausland. Politik und Ermordung des SA-Agenten Georg Bell (Geschichte, Bd. 18), Münster 1998, S. 119-138; Hancock, Eleanor: Only the Real, the True, the Masculine Held its Value. Ernst Röhm, Masculinity, and Male Homosexuality, in: Journal of the History of Sexuality 8 (1998) 4, S. 616-641, hier S. $633-636$.

80 Nieden/ Reichardt, Skandale, S. 42, die sich hier auf Zinn, Konstruktion, S. 55 - 76, beziehen.

81 Vgl. dazu Zinn, Exilpresse, S. 24f. Dort findet sich auch das Zitat.
} 
thematisiert. ${ }^{82}$ Darüber hinaus bildete die Inszenierung der "Röhm-Affäre» schon 1932/33 den Nährboden für das Entstehen erster Ansätze einer Faschismustheorie, die einen ursächlichen Nexus von sexueller Veranlagung (Homosexualität) und politischer Orientierung (Nationalsozialismus) konstruierte und darum bemüht war, einen diffusen Zusammenhang der Dispositionen zu Homosexualität, autoritären Strukturen, Sadismus und Gewalttätigkeit herzustellen. ${ }^{83}$

Im Frühjahr 1933 erkannten dann die Verfasser des "Braunbuchs» die Gunst der Stunde, als sie in ihrer Kampagne zum Reichstagsbrand die Behauptung in die Welt setzten, der Brandstifter Marinus van der Lubbe sei ein »Lustknabe» Ernst Röhms gewesen. Indem sie das Gerücht der homosexuellen Verschwörung und des nationalsozialistischen Sittenverfalls erneut aufgriffen, suggerierten sie äußerst geschickt, hinter dem Reichstagsbrand stehe eine homosexuelle Intrige, die einen essenziellen Wesenszug des Naziregimes offenlege. ${ }^{84}$ Obwohl es keine Belege für van der Lubbes angebliche Homosexualität gab, besaß diese Unterstellung eine enorme politische Sprengkraft und wurde schließlich im Herbst 1933 sogar im Reichstagsbrand-Prozess vor dem Reichsgericht in Leipzig thematisiert.

Röhm bemühte sich hingegen verstärkt darum, sein in der Öffentlichkeit angeschlagenes Image aufzupolieren. In der Beilage des "Völkischen Beobachters», dem »SA-Mann«, erschienen im Verlauf des Jahres 1933 mehrere Beiträge, in de-

82 Der Historiker Lothar Machtan versucht aus den spekulativen Verleumdungen der Exilpresse, schwachen zeitgenössischen Hinweisen und fragwürdigen Spekulationen den Beleg dafür zu konstruieren, "Hitlers Geheimnis" gelüftet und dessen "Doppelleben" aufgedeckt zu haben, wohinter sich die Hypothese verbirgt, dieser sei homosexuell veranlagt gewesen, habe dies aber mit allen erdenklichen Mitteln verdeckt. Auch Machtans Bemühen, den Machtkonflikt vom 30. Juni 1934 in eine reine Privataktion Hitlers umzudeuten, lebt einzig davon, dass die weithin akzeptierte Deutung der Röhm-Krise souverän beiseitegeschoben und deren spezifisch politische Dimension ausgeklammert wird. Vgl. Machtan, Hitlers Geheimnis, passim. Deutliche Kritik findet sich bei Mommsen, Hans: Viel Lärm um nichts, in: DIE ZEIT, Nr. 42 vom 11.10.2001.

83 Nieden, Aufstieg, S. 176; Zinn, Konstruktion, S. 44-47. Die wohl abstruseste homophobe Interpretationsleistung in diesem Zusammenhang wurde 1996 von Scott Lively und Kevin Abrams vorgelegt, die Röhms SA zum Produkt der Homosexuellenbewegung erklären. Mithilfe solcher Legendenbildungen wird der homophobe Gehalt des Nationalsozialismus schlicht de-thematisiert. Vgl. dazu Lively, Scott/ Abrams, Kevin: The Pink Swastika. Homosexuality in the Nazi Party, Oregon 1996. Dass die Thesen der beiden Autoren völlig unhaltbar sind, lässt sich schon daran ablesen, dass der evangelikale Missionar Lively Autor mehrerer antihomosexueller Bücher ist und an der Vorbereitung eines Gesetzes zur Verschärfung der Strafbarkeit von Homosexualität in Uganda beteiligt war, das die Todesstrafe für Homosexualität zur Folge gehabt hätte. Vgl. dazu Gettleman, Jeffrey: Americans’ Role Seen in Uganda Anti-Gay Push, in: New York Times, vom 3.1.2010; Alsop, Zoe: Uganda's Anti-Gay Bill: Inspired by the U.S., in: TIME, vom 10.12.2009.

84 Rabinbach, Anson: Van der Lubbe - ein Lustknabe Röhms? Die politische Dramaturgie der Exilkampagne zum Reichstagsbrand, in: Homosexualität und Staatsräson. Männlichkeit, Homophobie und Politik in Deutschland 1900 - 1945 (Geschichte und Geschlechter, Bd. 46), hrsg. von Susanne zur Nieden, Frankfurt a. M. 2005, S. 193 - 213, hier S. 200-205. Zur Debatte um den Reichstagsbrand vgl. Deiseroth, Dieter: Der Reichstagsbrand-Prozess - ein rechtsstaatliches Verfahren?, in: Kritische Justiz 42 (2009), S. 303 -316; Fischler, Hersch: Zum Zeitablauf der Reichstagsbrandstiftung. Korrekturen der Untersuchung Alfred Berndts, in: Vierteljahrshefte für Zeitgeschichte 55 (2005) 4, S. 617-632; Hehl, Ulrich von: Die Kontroverse um den Reichstagsbrand, in: Vierteljahrshefte für Zeitgeschichte 36 (1988) 2, S. 259 280 . 
nen der Stabschef als männlicher Kriegsheld und Träger der »Nationalen Revolution" dargestellt wurde. ${ }^{85}$ Trotz innerparteilicher Konflikte um seine erotischen Neigungen trat er in der NS-Bewegung zusätzlich eine Debatte über Moralvorstellungen los, die, obgleich verschlüsselt, das Dilemma eines NS-Führers berührten, der aufgrund seiner Homosexualität von politischen Gegnern wie angeblichen Parteifreunden zum Paria stilisiert worden war. Mit einem ungeschützt-energischen Vorstoß in dem Disput um Homosexualität und Moralvorstellungen wandte sich der in Parteikreisen zunehmend isolierte Stabschef dann am 8. September 1933 an sämtliche SA- und SS-Führer. In seiner öffentlichen Stellungnahme gegen die »Ausbreitung des Muckertums» gab er sich bewusst kämpferisch:

\begin{abstract}
"Offenbar in Ermangelung anderweitiger zweckmäßiger Betätigung widmen sich Einzelpersonen und Bünde der selbstgestellten Aufgabe, das deutsche Volk sittlich zu erneuern. Es ist unbestreitbar, dass das Muckertum in letzter Zeit geradezu Orgien feiert. Der deutschen Frau wird verboten, sich zu pudern und in Lokalen zu rauchen; in den Großstädten sollen alle irgendwie aus dem Spießerrahmen fallenden Vergnügungsstätten ausgerottet werden, gegen die sogenannte Prostitution wird ein Kampf geführt [...]. Ich will das Überhandnehmen derartiger, oft geradezu lächerlicher Auswüchse von Prüderie zum Anlaß nehmen, um einmal eindeutig festzustellen, daß die deutsche Revolution nicht von Spießern, Muckern und Sittlichkeitsaposteln gewonnen worden ist, sondern von revolutionären Kämpfern. [...] Ich verbiete daher sämtlichen Führern und Männern der SA und SS, ihre Aktivität auf diesem Boden einzusetzen und sich zum Handlanger verschrobener Moralästheten herzugeben. ${ }^{86}$
\end{abstract}

Auf den ersten Blick scheint es, als habe Röhm mithilfe seines Erlasses vor allem Frauen vor dem Moraleifer der NSDAP schützen wollen, doch viele ZeitgenossInnen erkannten gewiss die überdeutliche Kritik des Stabschefs an der homophoben Politik der neuen Regierung, auf die er nicht gerade subtil mit seinen Verweisen auf den "Harte Kämpfer-Erlass" Hitlers sowie auf das Feindbild des »Muckers», der einen Kampfbegriff der homosexuellen Emanzipationsbewegung darstellte, anspielte. ${ }^{87}$ Darüber hinaus berührte er in seiner Philippika ein tragendes Element der NS-Ideologie: das Konzept des Männerbundes, der wiederum ein we-

85 Dazu und zum Folgenden vgl. Nieden/ Reichardt, Skandale, S. 43; Hancock, Real, S. 619-623.

86 Röhm, Ernst: Eh. Nr. 1499/33. Betreff: Ausbreitung des Muckertums, in: Deutsche Freiheit 1 (28.9. 1933 ) 85, S. 8 (Hervorhebung im Original). Eine Abschrift ist außerdem im Bundesarchiv Berlin, Sammlung Schumacher, Bd. 414, überliefert. Bereits in der 1928 publizierten ersten Auflage seiner Biographie macht er keinen Hehl daraus, dass er eine Gesellschaft ablehne, die anstatt "gesunder Anerkennung natürlicher Vorgänge und Erkenntnisse Heuchelei, Lüge, Verstellung, Prüderie und unangebrachte Entrüstung vorschreibt«. Mit seiner Kritik richtete er sich zudem gegen die homophoben Vorbehalte in den eigenen Reihen: „Dass bestimmte völkische Kreise auch in dieses abgeleierte Jammerhorn blasen, um der Gesellschaft ihren Kotau zu machen, will mir gar nicht gefallen. Revolutionär erscheint mir diese Prüderie gewiss nicht, sondern bis zum Überdruss abgeschmackt und reaktionär.« Vgl. Röhm, Ernst: Die Geschichte eines Hochverräters, München 1928, S. 268.

87 Siehe dazu ausführlich Zinn, Konstruktion, S. 81-87; Jellonnek, Homosexuelle, S. 83. In den Zeitungen durfte nur eine weitgehend entschärfte und gekürzte Fassung gedruckt werden. Vgl. dazu bspw. Röhm, Ernst: Ausbreitung des Muckertums, in: Völkischer Beobachter, Nr. 270 vom 27.9.1933. 
sentliches Fundament des Männerstaates darstellte. ${ }^{88}$ Auf ihrem Weg zur Macht traten die Nationalsozialisten mit dem Versprechen an, die vermeintlich ins Wanken geratene Männlichkeit zu retten und wieder klare Grenzen zwischen den Geschlechtern ziehen zu wollen. ${ }^{89}$ Insbesondere in ihren frühen programmatischen Äußerungen verknüpften die Politiker der NSDAP die Felder "Politik» und "Geschlechtsidentität « auffällig eng miteinander. ${ }^{90}$ Deutschland sollte aus dem »Männerbund der Schützengräben« wiederaufstehen.

Als die Garanten einer männlichen Geschlechtsidentität und Politik der Tat galten vor allem der Ausschluss von Frauen aus dem politischen Leben und eine unbedingte Gewaltbereitschaft. ${ }^{91}$ Es waren der rapide soziale Wandel, die Abkehr von traditionellen Geschlechterrollen, die ökonomischen Krisen der Weimarer Jahre sowie die Gewalterfahrungen der Kriegs- und unmittelbaren Nachkriegszeit, die derart brachiale Rettungsfantasien in den 1920er Jahren auf verstärkten Widerhall stoßen ließen und den Aufstieg extremer politischer Ideologien, allen voran des Nationalsozialismus, begünstigten. ${ }^{92}$ Besonders zu Beginn der 1930er

88 Anfang der 2000er Jahre entbrannte in der "Zeitschrift für Geschichtswissenschaft» ein durch Lothar Machtan (Hitlers Geheimnis) ausgelöster Forschungsstreit über den Stellenwert, die Bedeutung sowie Interpretation von Männerbund, Homosexualität und Nationalsozialismus. Machtan hatte mit seinen Thesen dem Mythos vom homoerotischen Männerbund der SA Vorschub geleistet, mit dem sich bis heute antihomosexuelle Vorbehalte und heterosexuelle Entlastungsstrategien verbinden lassen. Unterstützung erhielt Machtan von Hans-Rudolf Wahl, in dessen Ausführungen das abwegige Konstrukt des "schwulen Nazis" nachhallt. Eine solch aberwitzige Perspektive versperrt freilich den Blick auf die Homosexualität als nationalsozialistischen Verfolgungsgrund; zu Recht kritisieren Sven Reichardt und Andreas Pretzel dieses Vorgehen. Vgl. Wahl, Hans-Rudolf: Männerbünde, Homosexualitäten und politische Kultur im ersten Drittel des 20. Jahrhunderts. Überlegungen zur Historiografie der SA, in: Zeitschrift für Geschichtswissenschaft 52 (2004) 3, S. 218-237; Reichardt, Sven: Homosexualität und SA-Führer. Plädoyer für eine Diskursgeschichte, in: Zeitschrift für Geschichtswissenschaft 52 (2004) 8, S. 737-740; Pretzel, Andreas: Homophobie und Männerbund. Plädoyer für einen Perspektivwechsel, in: Zeitschrift für Geschichtswissenschaft 53 (2005) 11, S. 1034-1044.

89 Wie George L. Mosse betont, waren die öffentlichen Debatten über Homosexualität stets von einer wachsenden Sorge hinsichtlich der möglichen Auflösung einer klar definierten männlichen Identität, erodierenden Grenzen zwischen den Geschlechtern und dem drohenden Verlust männlicher Privilegien geprägt. Vgl. Mosse, George L.: Das Bild des Mannes. Zur Konstruktion der modernen Männlichkeit, Frankfurt a. M. 1997, S. 92, 133.

90 Vgl. dazu Planert, Ute: Reaktionäre Modernisten. Zum Verhältnis von Antisemitismus und Antifeminismus in der völkischen Bewegung, in: Jahrbuch für Antisemitismusforschung 11 (2002), S. 31-51, hier S. 40 f. Zur identitätspolitischen Relevanz und zu der Konstruktion von Männlichkeit innerhalb (para)militärischer Verbände vgl. Kühne, Thomas: »...aus diesem Krieg werden nicht nur harte Männer heimkehren«. Kriegskameradschaft und Männlichkeit im 20. Jahrhundert, in: Männergeschichte - Geschlechtergeschichte. Männlichkeit im Wandel der Moderne (Geschichte und Geschlechter, Bd. 14), hrsg. von dems., Frankfurt a. M. 1996, S. 174-192; Seifert, Ruth: Identität, Militär und Geschlecht. Zur identitätspolitischen Bedeutung einer kulturellen Konstruktion, in: Heimat - Front. Militär und Geschlechterverhältnisse im Zeitalter der Weltkriege (Geschichte und Geschlechter, Bd. 35), hrsg. von Karen Hagemann/ Stefanie Schüler-Springorum, Frankfurt a. M. 2002, S. 53 - 66.

91 Zu Hitler als Mann der Tat, der wenig Neigung für das geschriebene Wort hatte und wiederholt zum Aktionismus aufrief, siehe auch Wildt, Michael: "Volksgemeinschaft" als politischer Topos in der Weimarer Republik, in: NS-Gewaltherrschaft. Beiträge zur historischen Forschung und juristischen Aufarbeitung (Publikationen der Gedenk- und Bildungsstätte Haus der Wannsee-Konferenz, Bd. 11), hrsg. von Alfred Gottwaldt/ Norbert Kampe/ Peter Klein, Berlin 2005, S. 23 - 39, hier S. 36 f.

92 Vgl. dazu Nieden, Susanne zur: Der homosexuelle Staatsfeind - zur Geschichte einer Idee, in: Ideen als gesellschaftliche Gestaltungskraft im Europa der Neuzeit. Beiträge für eine erneuerte Geistesge- 
Jahre gewann die radikale Re-Maskulinisierung des politischen Raumes, symbolisiert durch den politischen Soldaten, in hohem Maße an Relevanz. Dagegen galt der homosexuelle Mann vielen als unmännlich, weibisch und pervers - keinesfalls als viriler Männerheld. ${ }^{93}$ Ein "Männerstaat « wie das NS-Regime, so Heinrich Himmler in einer im Jahr 1937 gehaltenen Rede, laufe stets Gefahr, durch Homosexualität zerstört zu werden. ${ }^{94}$ Die Sorge, dass im kolportierten Bild des homosexuellen Nazis ein Fünkchen Wahrheit stecken könnte - so wahr wie die Tatsache, dass Röhms Homosexualität und nationalsozialistische Überzeugung sich nicht gegenseitig ausschlossen -, verfolgte die Machthaber und deren Repressionsorgane während der gesamten Herrschaftszeit des NS-Staates. Viele führende Nationalsozialisten wurden daher nicht müde, zu betonen, dass Homosexualität die Staatsräson unterminiere, da sie den bevölkerungspolitischen Zielsetzungen zuwiderlaufe und den "Männerstaat» in "seinen Grundfesten» bedrohe.95 Das manichäisch-binär geprägte Weltbild dieser Männer ließ eine homosexuelle Verschwörung durchaus als reale Gefahr für den NS-Staat erscheinen: zum Beispiel in Form eines Umsturzversuches, getragen von "homosexuellen Elementen" innerhalb der Partei. So erinnerte sich der eingangs erwähnte Werner Best im Jahr 1984 an eine Ansprache Himmlers, in der dieser den versammelten SS-Führern 1934 mitgeteilt habe, man sei »knapp der Gefahr entgangen, einen Staat von Urningen zu bekommen«. ${ }^{96}$

Die Fama einer homosexuellen Clique, die hinter den Kulissen einer Staatsmacht operiere und diese heimlich lenke oder sogar bedrohe, schien vielen schon deswegen äußerst plausibel, weil seit dem Kaiserreich immer wieder Gerüchte im Umlauf waren, wonach eine homosexuelle "Kamarilla" im Umkreis der Staatsführung existiere. ${ }^{97}$ Die inländische Presse, allen voran sozialdemokratische Zeitungen, hatte solche Legenden und Mythen stets aufgegriffen und in groß aufgemachten Kampagnen genüsslich skandalisiert und politisch instrumentalisiert.

schichte (Ordnungssysteme. Studien zur Ideengeschichte der Neuzeit, Bd. 20), hrsg. von Lutz Raphael/ Heinz-Elmar Tenorth, München 2006, S. 395 - 427, hier S. 411.

93 Vgl. u.a. Zinn, Konstruktion; Jellonnek, Homosexuelle; Siemens, Daniel: Erobern statt Verführen: Die Kategorie Geschlecht in der Politik der Straße der Weimarer Republik, in: Geschlechter(un)ordnung und Politik in der Weimarer Republik (Schriften der Stiftung Reichspräsident-Friedrich-Ebert-Gedenkstätte, Bd. 16), hrsg. von Gabriele Metzler/ Dirk Schumann, Bonn 2016, S. 255 - 277.

94 Dazu und zum Folgenden vgl. Nieden, Staatsfeind, S. 417f.; Dies./ Reichardt, Skandale, S. 58.

95 Rede Heinrich Himmlers aus dem Jahr 1937, zit. n. Nieden, Susanne zur: Homophobie und Staatsräson, in: Homosexualität und Staatsräson. Männlichkeit, Homophobie und Politik in Deutschland 1900 - 1945 (Geschichte und Geschlechter, Bd. 46), hrsg. von ders., Frankfurt a. M. 2005, S. 17-51, hier S. 20 .

96 Werner Best an Burkhard Jellonnek, 28.6.1984, zit. n. Jellonnek, Homosexuelle, S. 98. »Urning“ ist eine veraltete, aus dem 19. Jahrhundert stammende Bezeichnung für einen homosexuellen Mann.

97 Exemplarisch ist hier der Eulenburg-Skandal zu nennen, der die deutsche Öffentlichkeit von 1906 bis weit in die 1920er Jahre beschäftigte. Vgl. Domeier, Norman: Der Eulenburg-Skandal. Eine politische Kulturgeschichte des Kaiserreichs (Campus historische Studien, Bd. 55), Frankfurt a. M. 2010. 
Fazit

Die Fama einer homosexuellen Verschwörung eignete sich als narrativer Kern des "Röhm-Putsches« schon deswegen, weil antihomosexuelle Vorbehalte in der deutschen Bevölkerung quer durch alle politischen Lager weit verbreitet waren. So lässt sich auch den allerdings nur bedingt glaubhaften Stimmungsberichten der NS-Geheimdienste entnehmen, dass die von der Parteispitze gestrickte Legende einer unmittelbar drohenden Revolte homosexueller SA-Führer auf großen Widerhall stieß; zugleich erfüllte sie ihren Zweck, »einen breiten Konsens über die Beurteilung des Gewaltexzesses herzustellen«.98 Das Wissen um homosexuelle Männer in der SA-Führung verlieh ihr überdies so etwas wie einen wahren Kern. Offenkundig hatten die monatelange Gewöhnung an Gewalt wie auch die "Abscheu vor der despotischen SA" das allgemeine Rechtsempfinden der deutschen Bevölkerung bereits systematisch untergraben. ${ }^{99}$ Anstatt über den Massenmord aus Staatsräson schockiert zu sein, akzeptierte sie die Legende, die von den Mördern aufgetischt wurde; teilweise begrüßte sie die blutige Zerschlagung der SA sogar ausdrücklich.

In Anbetracht der Krisenstimmung 1933/34, der Abnahme des wirtschaftlichen Aufschwunges und der ansteigenden Unzufriedenheit in der Bevölkerung erwiesen sich die angeordneten Gewalttaten für die Festigung des NS-Herrschaftssystems als überaus nützlich. Mit dem Mordkomplott gegen ihre wichtigsten Führer verlor die SA an Einfluss und die Verschwörer beendeten auf diese Weise die anhaltenden Konflikte um die Fortsetzung einer "Deutschen Revolution«. Weiterhin kam die neue Regierung mit der Entmachtung der SA den Forderungen der Reichswehr nach, die sich durch Röhms Volks-Heer bedroht fühlte. So gesehen festigten sowohl die Parteiorganisation der NSDAP als auch die Reichswehr mithilfe eines mörderischen Ränkespiels ihre vermeintlich oder tatsächlich bedrohte Position, zumal man dadurch außerdem unbequeme Regimekritiker losgeworden war und eine mögliche Opposition im Keim erstickt hatte. ${ }^{100}$ Und insbesondere Himmler konnte sich eines lästigen Konkurrenten entledigen, der für sein Imperium aus SS, SD, Gestapo und Konzentrationslagern ein enormes Hindernis gewesen war; der Mord an Röhm markierte für die SS den Durchbruch zur einflussreichsten Machtgruppe im nationalsozialistischen Regime. Zweifellos ging es der NS-Führung bei dem Mordkomplott vom 30. Juni 1934 also in erster Linie darum, die eigene machtpolitische Stellung auszubauen und zu sichern.

\footnotetext{
98 Nieden, Aufstieg, S. 187.

99 Kershaw, Hitler, S. 654. Siehe dort auch zum Folgenden.

100 Nieden/ Reichardt, Skandale, S. 56.
} 
Bezeichnend ist dennoch, wie eng bei dieser Form der Machtsicherung die Felder "Politik» und "Männlichkeit» miteinander verknüpft wurden. ${ }^{101}$ Die Eskalation staatlicher Gewalt wurde in eine öffentliche Auseinandersetzung über Sexualität und Moral gebettet, wodurch man hoffte, diese Grenzüberschreitung legitimieren zu können. Während Ernst Röhm seine Kritik am prüden und spießigen "Muckertum» noch mit dem Vorwurf "nationalrevolutionärer Lauheit» kombiniert hatte, präsentierte sich Adolf Hitler nun »als Mann der Gewalttat», der keine Skrupel besaß, den "moralischen Sumpf" gnadenlos und brutal auszutrocknen, womit in erster Linie freilich die Homosexuellen in den eigenen Reihen gemeint waren.

Blickt man abschließend auf die bunt gemischte Koalition der Röhm-Gegner, die sich aus Parteiführern wie Rudolf Heß und Heinrich Himmler, Reichsministern wie Wilhelm Frick oder Hermann Göring, Nebenfiguren wie Viktor Lutze und Reichswehrangehörigen wie Werner von Fritsch und Werner von Blomberg rekrutierte, dann wird augenfällig, dass es sich bei den Ereignissen, die zum 30. Juni 1934 führten, um keinen drohenden Putsch durch Röhm gehandelt hat, wie die bis heute gebräuchliche Bezeichnung suggeriert, sondern vielmehr um einen »Putsch gegen Röhm». Erst mithilfe einer überwiegend unbegründeten Angst vor einer zweiten nationalsozialistischen Revolution, die von einer Clique homosexueller SA-Führer angeblich im Verborgenen geplant wurde, welche sich überdies mit innerparteilichen Konkurrenten und konservativen Kritikern des Regimes verschworen hätten, konnte jene nachträglich als Staatsnotwehr verschleierte Mordaktion gesetzlich legitimiert werden. Diese ermöglichte es der NSDAP, eine nach und nach labile »Vermittlungsdiktatur «102 zu etablieren, die zwischen radikalen Parteiführern und konservativen Gruppen aus Armee, Industrie und Bürokratie vermittelte.

101 Dazu und zum Folgenden ebd., S. 57. Dort finden sich auch die Zitate. Vgl. dazu auch Zinn, Alexander: SA, Homosexualität und Faschismus. Zur Genese des Stereotyps vom schwulen Nazi, in: Bürgerkriegsarmee. Forschungen zur nationalsozialistischen Sturmabteilung (SA), hrsg. von Yves Müller/ Reiner Zilkenat, Frankfurt a. M. 2013, S. 393 -413, hier S. 401; sowie die Überlegungen bei Dietrich, Anette/ Heise, Ljiljana: Perspektiven einer kritischen Männlichkeitenforschung zum Nationalsozialismus. Eine theoretische und pädagogische Annäherung, in: Männlichkeitskonstruktionen im Nationalsozialismus. Formen, Funktionen und Wirkungsmacht von Geschlechterkonstruktionen im Nationalsozialismus und ihre Reflexion in der pädagogischen Praxis (Zivilisationen \& Geschichte, Bd. 18), hrsg. von dens., Frankfurt a. M. 2013, S. 7-35, insb. S. $18-20$.

102 Vgl. Schieder, Wolfgang: Das Deutschland Hitlers und das Italien Mussolinis. Zum Problem faschistischer Regimebildung, in: Die große Krise der dreißiger Jahre. Vom Niedergang der Weltwirtschaft zum Zweiten Weltkrieg, hrsg. von Gerhard Schulz, Göttingen 1985, S. 44 - 71; Paxton, Robert O.: The Anatomy of Fascism, New York 2004, S. $106-110$. 